\title{
Access to finance, product innovation and middle-income traps
}

DOI:

10.1016/j.rie.2017.03.004

\section{Document Version}

Accepted author manuscript

Link to publication record in Manchester Research Explorer

\section{Citation for published version (APA):}

Agénor, P. R., \& Canuto, O. (2017). Access to finance, product innovation and middle-income traps. Research in Economics. https://doi.org/10.1016/j.rie.2017.03.004

\section{Published in:}

Research in Economics

\section{Citing this paper}

Please note that where the full-text provided on Manchester Research Explorer is the Author Accepted Manuscript or Proof version this may differ from the final Published version. If citing, it is advised that you check and use the publisher's definitive version.

\section{General rights}

Copyright and moral rights for the publications made accessible in the Research Explorer are retained by the authors and/or other copyright owners and it is a condition of accessing publications that users recognise and abide by the legal requirements associated with these rights.

\section{Takedown policy}

If you believe that this document breaches copyright please refer to the University of Manchester's Takedown Procedures [http://man.ac.uk/04Y6Bo] or contact uml.scholarlycommunications@manchester.ac.uk providing relevant details, so we can investigate your claim.

\section{OPEN ACCESS}




\section{Accepted Manuscript}

Access to Finance, Product Innovation and Middle-Income Traps

Pierre-Richard Agénor, Otaviano Canuto

PII:

S1090-9443(16)30326-X

DOI:

10.1016/j.rie.2017.03.004

Reference:

YREEC 716

To appear in:

Research in Economics

RESEARCH IN

ECONOMICS $\ldots$

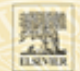

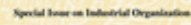

Received date:

27 December 2016

Revised date: 3 March 2017

Accepted date: $\quad 9$ March 2017

Please cite this article as: Pierre-Richard Agénor, Otaviano Canuto, Access to Finance, Product Innovation and Middle-Income Traps, Research in Economics (2017), doi: 10.1016/j.rie.2017.03.004

This is a PDF file of an unedited manuscript that has been accepted for publication. As a service to our customers we are providing this early version of the manuscript. The manuscript will undergo copyediting, typesetting, and review of the resulting proof before it is published in its final form. Please note that during the production process errors may be discovered which could affect the content, and all legal disclaimers that apply to the journal pertain. 


\section{Highlights}

- Interactions between access to finance, product innovation, and labor supply are studied in an OLG model

- Distribution of skills is endogenous

- Lack of access to finance has an adverse effect on innovation activity, directly and indirectly

- indirect effect operates through decision to invest in skills

- Multiple steady states may emerge if monitoring costs fall with number of successful projects

- One is a middle-income trap, with small labor force and low wages in innovation, and low growth

- Alleviating constraints on access to finance may help to escape from that trap.

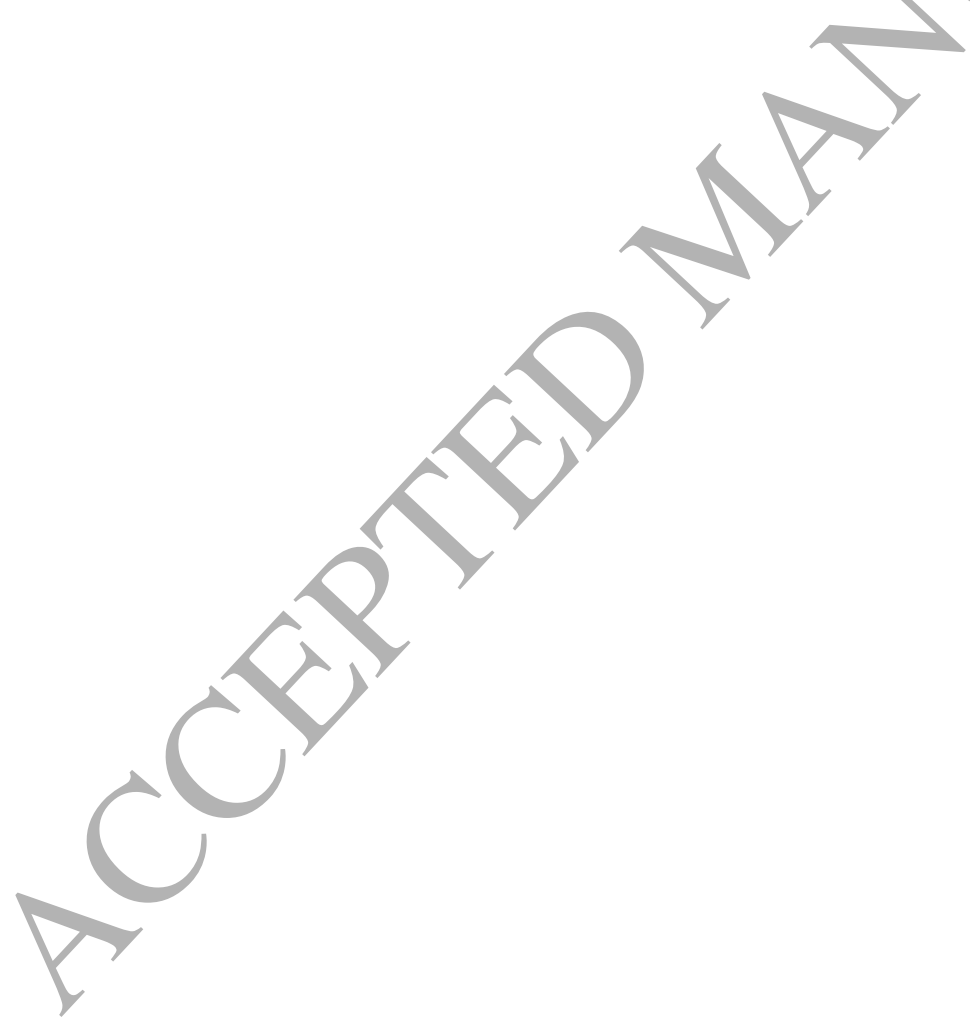




\title{
Access to Finance, Product Innovation and Middle-Income Traps
}

\author{
Pierre-Richard Agénor* and Otaviano Canuto**
}

\author{
Final version: March 15, 2017 \\ Forthcoming, Research in Economics
}

\begin{abstract}
Interactions between access to finance, product innovation, and labor supply are studied in a two-period overlapping generations model with an endogenous skill distribution and financial market imperfections. In the model lack of access to finance (induced by high monitoring costs) has an adverse effect on innovation activity not only directly but also indirectly, because too few individuals may choose to invest in skills. If monitoring costs fall with the number of successful projects, multiple steady/states may emerge, one of which defined as a middle-income trap, characterized by low wages in the design sector, a low share of the labor force engaged in innovation activity, and low growth. A sufficiently ambitious policy aimed at alleviating constraints on access to finance by innovators may allow a country to move away from such a trap by promoting the production of ideas and improving incentives to invest in skills.
\end{abstract}

JEL Classification Numbers: O31, G20, O41.

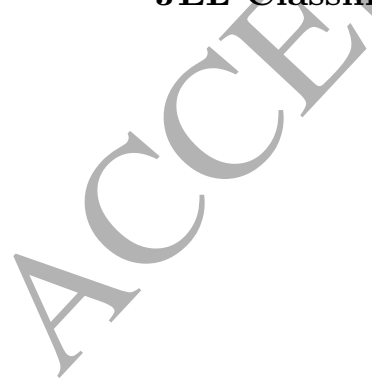

*School of Social Sciences, University of Manchester; ${ }^{* *}$ World Bank. We are grateful to participants at various seminars and the Editor for helpful discussions and comments. However, we bear sole responsibility for the views expressed in this paper. 


\section{Introduction}

The impact of financial constraints on innovation has been the subject of much debate in recent years. The conventional view is that firms engaged in innovation may suffer from a variety of frictions that may limit their ability to resort to external finance. Assets held by these firms are mainly intangible; as a result, they may lack collateral value. For instance, spending in the form of salaries and wages for scientists and researchers, which often represent a large fraction of innovation-related activities and help to build human capital, cannot be collateralized. Furthermore, to protect their proprietary information over innovation, firms may be unwilling to offer fully transparent signals about the effectiveness of their intended innovation programs to potential lenders. Limited collateral value and information frictions may thus help to explain why some of these firms rely little on debt finance and instead fund most of their investments with their own resources or (at later stages) equity. Indeed, the high degree of information asymmetry that characterizes investment in innovation projects may induce lenders to demand higher rates of return than in the case of investments in physical assets. Thus, although information asymmetries matter for external financing of all types of investments, they may be particularly significant in limiting financing of innovation projects due to the complexity and specificity of the innovation process. Moreover, funding through equity is either costly - especially for firms whose values are determined mainly by their growth potential and hence are severely exposed to asymmetric information frictions - or simply not available, as is often the case for younger and smaller firms. ${ }^{1}$ If financing constraints are binding for a sufficient number of innovative firms, economic growth may be adversely affected.

Although at the conceptual level there are good reasons to believe that information problems and lack of collateral value can make innovation activities more susceptible to financing frictions than other types of investment, the early evidence did not prove

${ }^{1}$ The inability of innovative firms to raise external capital can be mitigated in countries where venture capitalists (VCs) operate. The theoretical literature in financial economics on how VCs screen, select, and finance small firms is largely partial equilibrium in nature and focuses on the dynamics of the relationship and optimal contractual arrangements between VCs and entrepreneurs. See for instance Keuschnigg (2003) for references and a simple model of contractual arrangement with double moral hazard. 
very conclusive. As noted by Hall and Lerner (2010) in a comprehensive review of the literature, although some studies provided evidence that financial frictions have a strong adverse effect upon innovation, others failed to find any significant effect. However, more recent studies have shown that the early literature suffered from several deficiencies. One problem is that in some early studies financial constraints were measured using the sensitivity of investments to internally generated cash flows; but because they are positively correlated with expected profits, traditional cash-flow indicators may fail to identify meaningful patterns in the data. Other problems include the use of inadequate controls, the presence of bias arising from the endogeneity of the variable(s) measuring financial constraints, and sampling issues. More recent studies that address these econometric issues all point to significant negative effects of financial barriers on the ability of firms to engage in innovation. ${ }^{2}$

As discussed next, several analytical contributions have attempted to identify more precisely the channels through which inadequate access to finance may act as a constraint to innovation and, in doing so, adversely affect growth. However, none of these studies explores the possibility that interactions between financial constraints, innovation and growth may lead to multiple steady states. Models of this type are useful because they highlight the importance of substantive policy changes to escape from a "bad" equilibrium; in addition, they also help to emphasize the fact that temporary, properly targeted interventions can have permanent consequences.

Accordingly, this paper presents an analysis of how interactions between access (or lack thereof) to finance, product innovation, and labor supply can generate multiple steady states, one of which defined as a middle-income trap characterized by persistent low growth in output, low productivity, and possibly a misallocation of talent. Rather than slow (or lack of) convergence to a unique equilibrium due to cross-country differences in structural parameters and public policies, as emphasized in the conventional literature on growth empirics (see Agénor ((2004), Aghion and Howitt (2009), and

\footnotetext{
${ }^{2}$ Although these studies pertain mostly to industrial countries, some also include developing countries. Empirical studies and enterprise surveys have indeed documented that lack of access to finance is one of the most important constraints that formal private firms - small and medium-size alike face in developing countries. See for instance World Bank (2008, 2012), Dinh and Clarke (2012), and International Finance Corporation (2013).
} 
Acemoglu (2009) for instance), our analysis is predicated on the view that a middleincome trap is best seen as a "bad" equilibrium among many_bad but nonetheless stable, in the sense of being a persistent state to which the economy gravitates unless some significant shock, structural or otherwise, occurs. Studies by Eichengreen et al. (2012, 2014), Felipe et al. (2012), Jimenez et al. (2012), Aiyar et al. (2013), and Im and Rosenblatt (2013) have attempted to provide evidence on the existence of these traps. While legitimate questions have been raised about the robustness of the cross-country evidence (including those that have plagued the literature on growth empirics in general), this does not invalidate the fact that the concept of a middle-income trap is useful to understand the experience of individual countries and the policy challenges that growth transitions present to them. ${ }^{3}$ In a previous contribution (see Agénor and Canuto (2015)), we emphasized the role of accéss (or lack thereof) to advanced infrastructure, especially information and telecommunications technologies, and their interaction with labor supply decisions, as a source of middle-income traps. In the present paper we shift our emphasis to access to finance, while continuing to account for the endogeneity of the decisions to invest in skills and to innovate. As it turns out, this is important to understand the interactions between finance and innovation.

More specifically, we combine elements of our previous framework with some features of the analysis presenteed in Morales (2003), in order to bring forth the role of financial market imperfections. Our analysis shows that if research activity involves borrowing from financial intermediaries and monitoring is costly, high intermediation costs may adversely affect innovation. This is in line with some of the other contributions discussed earlier. In addition, if monitoring costs are high, fewer individuals may choose to invest in skills and engage in design activities. The reason is that high monitoring costs lead to lower wages in the design sector, which in turn lead (for a given cost of education) to reduced incentives to invest in skills and thus a lower share of the labor force engaged in research. From that perspective, lack of access to finance

\footnotetext{
${ }^{3}$ See Agénor (2017) for a critical review of the evidence. As discussed in that paper, a middleincome trap differs from a poverty trap - an issue that has been studied extensively in the literature, see Azariadis (2006) - by the fundamental source of multiple equilibria: in a middle-income trap it is the lack of innovation activity that may prevent a country from escaping a low- or moderate- growth equilibrium rather than, say, low savings, poor nutrition, lack of basic infrastructure, etc., as typically observed in low-income countries.
} 
not only has a direct, adverse effect on innovation activity and growth, but also an indirect effect that operates in the same direction. We also show that if unit monitoring costs fall with the number of successful projects (as a result of information externalities, for instance), multiple steady states may emerge - one of which, a middle-income trap, characterized by low wages in the design sector, a low share of the labor force engaged in innovation activity, and low growth. A sufficiently ambitious policy aimed at alleviating financial constraints - through the development of capital markets rather than government subsidies, which may be difficult to target effectively-may allow a country to move away from such a trap, not only by reducing the cost of finance but also by improving incentives to invest in skills and promoting the production of ideas.

The focus of our analysis is on middle-income countries, where we believe that accounting for the labor market effects of access to finance (or lack thereof) is particularly important to understand the interactions between financial intermediation, innovation, and growth. In these countries, the supply of highly-qualified labor remains relatively limited, creating therefore another constraint on innovation activity. By contrast, in developed countries the issue máy be less about the quantity of highlyskilled workers and more about the allocation of talent - an issue that we addressed in our previous contribution and the provision of adequate incentives to engage in risky entrepreneurial activities. Nevertheless, our analysis also has some relevance for slow-growing industrial countries. Indeed, there is compelling empirical evidence to suggest that in many of these countries access to finance remains an equally important constraint on the innovation activity of small and medium-sized firms. Such constraint may therefore be the source of a slow-growth steady state, just as with the middleincome trap that we characterize in our analysis. In such conditions, a forceful policy aimed at promoting access to finance is also essential to escape from a low-growth steady state and put the economy on a path that would allow it to converge to a high-growth, high-innovation steady state.

The paper proceeds as follows. Section 2 sets the stage by reviewing analytical contributions, as well as recent empirical evidence, on the link between financial constraints, innovation, and growth. The model is described in Section 3. Section 4 defines the equilibrium and analyzes its properties. Section 5 discusses the conditions under 
which multiple steady states may emerge, when unit monitoring costs are endogenous. Section 6 draws together the policy implications of the analysis, and the final section offers some concluding remarks.

\section{Background}

Analytical contributions that have attempted to identify the channels through which inadequate access to finance may act as a constraint to innovation and, in doing so, adversely affect growth include Galetovic (1996), De la Fuente and Marín (1996), Blackburn and Hung (1998), Morales (2003), Aghion et al. (2005), Gorødnichenko and Schnitzer (2013), and Laeven et al. (2015).

De la Fuente and Marín (1996) for instance developed a model of product innovation in which efficiency of the financial system arises endogenously. Risk aversion and private information in innovation activities lead to a moral hazard problem, and this makes innovative activity unattractive for risk-averse entrepreneurs. ${ }^{4}$ This problem, however, can be mitigated through improved monitoring, which allows financial intermediaries to offer better insurances terms. Hence, more efficient financial systems yield a higher level of innovative activity. Blackburn and Hung (1998) study an economy in which firms require external finance to engage in innovation activity but are subject to a moral hazard problem, due to the fact that the outcome of such activities is private information - only the firm itself can directly observe if the innovation activity has succeeded in producing a new blueprint. Because the solution to this problem (in standard Gale-Hellwig-Townsend fashion) is in terms of an incentive-compatible loan contract that involves costly monitoring, a fixed cost is introduced in the innovation sector Financial liberalization allows financial intermediaries to diversify among a large number of projects that significantly reduces delegation costs. Lower costs of monitoring therefore spur innovation activity and economic growth.

Morales (2003) also explicitly modeled the contractual relationship between innova-

\footnotetext{
${ }^{4}$ In their model, it is the actions of firms, rather than the outcomes of projects, that are imperfectly observable by lenders. In addition, the precision of information obtained by lenders depends on the intensity of monitoring activity, and the feedback between growth and financial development occurs as a result of changes in factor prices.
} 
tors (researchers) and lenders. Financial intermediaries are endowed with a monitoring technology that allows them to force researchers to exert a higher level of effort than the one they would choose in the absence of monitoring. Hence, research productivity, and the likelihood of research projects succeeding, is determined in the credit market and thus may be affected by the nature of financial contracts. The promotion of financial activities (through subsidies to financial intermediation, for instance) may therefore increase productivity in the innovation sector and enhance the economy's growth performance. ${ }^{5}$ Aghion et al. (2005) assumed that firms can conceal the results of successful innovations and thereby avoid repaying their creditors. A low degree of creditor protection makes fraud an inexpensive option, and this limits firms' access to external finance - which in turn discourages the production of ideas. ${ }^{6}$ Financial liberalization tends to increase hiding costs by providing better laws and institutions. This makes credit more readily available to entrepreneurs and allows them to engage in more innovation-related activities. Moreover, Aghion and Howitt (2009, Chapter 6) showed in a related setting that reducing credit constraints results in lower screening and monitoring costs, thus mitigating agency problems and increasing the frequency of innovations. Finally, Gorodnichenko and Schnitzer (2013) developed a model with monopolistic competition, financial constraints, and innovation activities, and derived two important results. First, the stronger internal financial constraints (induced by negative liquidity shocks) are, the lower is the investment in innovation or knowledge creation activities in general. Second, the more severe external financial constraints (that is, the larger the cost of external finance) are, the more pronounced is the impact of a negative liquidity shock on innovation. Put differently, even though firms may tend to use internal funds to finance innovation projects, the cost of external finance

\footnotetext{
${ }^{5}$ In addition, Morales also found that a subsidy to financial intermediation may be more effective than a direct/subsidy to research. The latter policy induces a higher research intensity that raises the growth rate. However, the tax change reduces researchers' incentives to exert effort, which implies higher monitoring costs and lower productivity in the innovation sector. This mitigates the positive growth effect of the research subsidy to a point where, for a high enough subsidy rate, the growth effect can become negative.

${ }^{6}$ Acharya and Subramanian (2009) have argued, on the contrary, that a low degree of creditor protection may discourage the production of ideas. But they do so in a model in which innovators may choose between debt and equity, a questionable assumption for the type of countries that are the focus of this paper.
} 
may also alter incentives to innovate, because it can affect the firms's production costs and overall profitability.

Recent empirical contributions on the link between access to finance and innovation include Savignac (2008), De Mel et al. (2009), Ang (2010, 2011), Ayyagari et al. (2011), Hirukawa and Ueda (2011), Ilyina and Samaniego (2011), Brown et al. (2012), Efthyvoulou and Vahter (2012), Hottenrott and Peters (2012), Maskus et al. (2012), Popov and Roosenboom (2012), Silva and Carreira (2012), Gorodnichenko and Schnitzer (2013), Faria and Barbosa (2014), and Hsu et al. (2014).

Using a direct measure of financial constraints faced by French firms, Savignac (2008) estimated simultaneously the probability to have innovative activities and the probability to face financial constraints. She also accounted for the endogeneity of the financial constraint variable, by relating it to firms' $e x$ ante financing structure and economic performance. She found that financial constraints significantly reduced the likelihood of firms engaging in innovative activities. Similarly, Efthyvoulou and Vahter (2012) found that lack of appropriate sources of finance is an important hampering factor to innovation performance across European countries, whereas Hottenrott and Peters (2012) found that external financial constraints are more binding for R\&D and innovation activities of small firms.

Ayyagari et al. (2011) exploited the responses of some 17,000 firms in 47 countriesmany of them low- and middle-income economies - to questions on enterprise innovation. Taking an average of each firm's responses to the innovation-related questions, they assembled a range of country- and firm-level variables likely to be associated with firm innovation, including information about the structure of each firm's financing. Accounting for yarious control variables and controlling for reverse causality by using instrumental variable techniques, they found that firms' use of external finance was associated with more innovation.

In the same vein, Ilyina and Samaniego (2011) found, using cross-country data, that industries that grow faster in more financially developed countries display greater research and development $(\mathrm{R} \& \mathrm{D})$ intensity and investment lumpiness, indicating that well-functioning financial markets direct resources towards industries where growth is driven by R\&D. In a study of 16 European countries, Brown et al. (2012) also found 
strong evidence that the availability of finance does matter for $\mathrm{R} \& \mathrm{D}$, once firms' efforts to smooth $R \& D$ with cash reserves and firms' use of external equity finance are directly controlled for. They conclude that stock market development and liberalization can promote economic growth by increasing firm-level innovative activity.

Cross-country studies by Ang (2011), Maskus et al. (2012), and Hsu et al. (2014) go in the same direction regarding the link between financial development and innovation. Using data for 44 developed and developing countries over the period 1973-2005, Ang (2011) found that financial development (as measured by the ratio of private sector credit to GDP) has a positive impact on the accumulation of ideas (as measured by the growth of patents), possibly by mitigating the effect of financial/constraints.

In an analysis of the performance of 22 manufacturing industries in 18 OECD countries, Maskus et al. (2012) found that bank credit and stock-market capitalization have similar effects, in terms of magnitude, on R\&D intensities (defined as industrylevel R\&D as a share of output). Financial development and financial access are key reasons why firms in countries with deeper markets invest more in $R \& D$ than do their counterparts in other countries. They also found that industries with low proportions of tangible capital tend to be those with higher proportions of intellectual capital. If the R\&D intensities of those sectors also rise with capital-market sophistication, then financial development would support higher innovation in knowledge-based activities. In the same vein, Hsu et al. (2014) found that equity market development tends to promote innovation in industries that are not only more dependent on external finance but also more high-tech intensive.

De Mel et al (2009), Ang (2010), and Silva and Carreira (2012) are three country case studies on the link between access to finance and innovation. Using survey data for Sri Lanka, De Mel et al. (2009) found that access to finance (as measured by the presence of a bank loan) is positively correlated with the capacity to innovate. However, this correlation could also reflect unmeasured productivity attributes of the firm that are correlated with both its ability to innovate and its decision to receive a loan. Using data for the Republic of Korea over the period 1967-2005, Ang (2010) found a significant long-run relationship between knowledge production and financial liberalization. By analyzing the impact of a self-assessed measure of constraints upon 
R\&D investment, Silva and Carreira (2012) found that, when the endogeneity problem associated with that variable is taken into account, financial constraints significantly decrease the amounts invested in R\&D in Portugal. Furthermore, also resorting to the same direct measure, they found that innovation (in a broad sense) is significantly hampered by financial constraints only once they allow for a joint specification of errors of both equations.

Studies by Hirukawa and Ueda (2011), Popov and Roosenboom (2012), and Faria and Barbosa (2014) focus more specifically on the link between venture capital (VC) and innovation. The key question asked by Hirukawa and Ueda (2011) is related to the causal relationship between VC and innovation: does VC investment make the invested firms innovative, or do innovative firms attract VC investment? This in turn rests on the validity of the "VC-first" (VC induces innovation) versus "innovation-first" (the arrival of new technology that spurs the demand for VC) hypotheses. They argue that the earlier literature (reviewed by Sharpe (2009) and Hall and Lerner (2010)) was often viewed as being supportive of the VC-first hypothesis. However, they provide a more careful analysis of the causality between VC and innovation by studying two types of $\mathrm{VC}$ investments (the first and follow-on investments) and two innovation indicators (patent counts and TFP growth) in a panel of U.S. manufacturing industries. They found distinct results for each indicator and each type of VC investment. In relation to patent growth in the first $\mathrm{VC}$ investment, there is little evidence to support either the innovation-first or the VC-first hypotheses but VC appears to slow down patent growth one year later.

Popov and Roosenboom (2012) provide apparently the first cross-country evidence of the effect of $\mathrm{VC}$ investment on patented inventions. Using a panel of 21 European countries and 10 manufacturing industries covering the period 1991-2005, they study the effect of $\mathrm{VC}$, relative to $\mathrm{R} \& \mathrm{D}$, on the number of granted patents. They address concerns about causality by exploiting variations across countries and over time in private equity fund-raising and in the structure of private equity funds. They found that the effect of $\mathrm{VC}$ is significant only in the subsample of high-VC countries, where the ratio VC/R\&D has averaged around 3.9 percent between 1991 and 2005 and VC has accounted for 10.2 percent of industrial innovation during that period. They also found 
that $\mathrm{VC}$ is relatively more successful in fostering innovation in countries with lower barriers to entrepreneurship, with a tax and regulatory environment that promotes venture capital investment, and with lower taxes on capital gains. Faria and Barbosa (2014) also found robust empirical support for a positive impact of VC on innovation on a sample of 17 European countries.

The thrust of the foregoing discussion is therefore that more recent empirical studies, which address a range of econometric problems that plagued the earlier literature (inadequate controls, endogeneity bias, direction of causality, sampling issues, and so on) tend to a large extent to support the existence of significant negative effects of financial constraints on the ability of firms - especially the smaller ones - to engage in innovation, as identified in a number of analytical contributions. This is especially so for studies that use direct indicators based on firm's own assessments. We now turn to a formal analysis of the link between financial constraints in a growth framework with endogenous skills acquisition.

\section{The Economy}

The economy that we consider is populated by individuals with different innate abilities, who live for two periods, adulthood and old age. In each period $N$ agents are born. Each individual is endowed with one unit of time in the first period of life, and zero unit in old age. Wages are the only source of income in adulthood.

There are three production sectors in the economy: the first produces a final good (manufacturing, for simplicity), the second intermediate inputs (which depreciate fully after use), and the third designs. As in Romer (1990), each new design involves the production of a new intermediate input, using a technology similar to the one used to produce the final good. Firms producing the final good use unskilled labor, physical capital, and intermediate goods, whereas firms in the design sector (or researchers, for short) use only skilled labor. The final good can be either consumed in the period it is produced, or stored to yield physical capital at the beginning of the following period. Innovation activity is risky and requires external finance of researchers' wages, as they do not accept uncertain returns. Therefore, access to finance partly determines 
the size of the innovation sector and the allocation of labor across sectors. As in Besanko and Kanatas (1993) and Morales (2003), the contractual relationship between researchers and lenders involves monitoring; the monitoring technology that financial intermediaries are endowed with allows them to induce researchers to exert a higher level of effort than the one they would choose in the absence of monitoring. In a sense, the absence of "skin in the game," due to the fact that intangible capital cannot be used as collateral to secure financing for innovation (as documented by the evidence) means that monitoring is critical to create incentives for repayment.

\subsection{Households}

Individuals have identical preferences but they are born with different abilities, indexed by $a_{t}$. Ability is instantly observable by all; it follows a continuous distribution with density function $f\left(a_{t}\right)$ and cumulative distribution function $F\left(a_{t}\right)$, with support $(0,1)$. For tractability, we assume that $F$ is continuously differentiable, strictly increasing, with a time-invariant function, and common to all individuals. Each individual maximizes utility and decides whether to enter the labor force as an unskilled worker or (following a training period) as a skilled worker. Unskilled individuals can only work in the final good sector, whereas only skilled workers can work in the design sector. Each individual knows his (her) own ability level, as do all the firms that might potentially hire him (her). ${ }^{7}$

An individual with ability $a_{t}$ can choose to enter the labor force at the beginning of adulthood (period $t$ ) as an unskilled worker and earn the wage $w_{t}^{U}$, which is independent of the worker's ability. Alternatively, at the start of adult life (before entering the labor market) the individual may choose to undergo training to acquire additional, specialized skills. As in Tanaka and Iwaisako (2009), in order to acquire skills young agents must devote $\min \left(1+\mu-a_{t}, 1\right)$ units of time to education, where $0 \leq \mu<1$ is a constant. Thus, more able individuals spend less time in training. Young agents with ability $a_{t}$ who choose to acquire skills can supply only $\max \left(a_{t}-\mu, 0\right)$ units of skilled labor.

\footnotetext{
${ }^{7}$ To avoid a corner solution where all workers become skilled and final output (as defined later) is zero, it could be assumed that individuals with ability $a_{t} \in\left(0, a_{m}\right)$ never choose to undergo training. However, this would not qualitatively affect our analysis.
} 
For simplicity, we assume that agents incur no other costs to acquire education. By contrast, an agent who chooses not to invest in skills can supply one unit of unskilled labor.

Formally, an individual with ability $a_{t}$ chooses to receive higher education if and only if the wage earned by supplying skilled labor, $\left(a_{t}-\mu\right) w_{t}^{S}$, is at least equal to that of unskilled labour, $w_{t}^{U}$, that is, $\left(a_{t}-\mu\right) w_{t}^{S} \geq w_{t}^{U}$. This condition defines therefore a threshold level of ability $a_{t}^{C}$ such that all individuals with ability lower than $a_{t}^{C}$ choose to remain unskilled:

$$
a_{t}^{C}=\omega_{t}+\mu,
$$

where $\omega_{t}=w_{t}^{U} / w_{t}^{S}$ is the unskilled-skilled wage ratio.

Exploiting the law of large numbers, the supply of unskilled and skilled labour can be written as

$$
\begin{gathered}
N_{t}^{U}=\int_{0}^{a_{t}^{C}} N d F(a), \\
N_{t}^{S}=\int_{a_{t}^{C}}^{1} N\left(a_{t}-\mu\right) d F\left(a_{t}\right),
\end{gathered}
$$

as long as $a_{t}^{C}<1$, given the restriction on the distribution of abilities. Thus, $N_{t}^{U}$ is increasing in $\omega_{t}$ whereas $N_{t}^{S}$ is decreasing in $\omega_{t}$.

Assuming for simplicity a uniform distribution of abilities, so that $F(a)=a$, yields

$$
\begin{gathered}
N_{t}^{U}=N a_{t}^{C} \\
N_{t}^{S}=0.5 N\left[1-\left(a_{t}^{C}\right)^{2}\right] .
\end{gathered}
$$

Let $c_{t+j}^{a, t}$ denote consumption at period $t+j$ of an individual with ability $a$, born at the beginning of period $t$, with $j=0,1$. The individual's discounted utility function is given by

$$
V_{t}^{a}=\ln c_{t}^{a, t}+\frac{\ln c_{t+1}^{a, t}}{1+\rho}
$$

where $\rho>0$ is the discount rate.

The period-specific budget constraints are given by

$$
\begin{gathered}
c_{t}^{a, t}+s_{t}^{a}=\max \left[\left(a_{t}-\mu\right) w_{t}^{S}, w_{t}^{U}\right], \\
c_{t+1}^{a, t}=R_{t+1}^{K} s_{t}^{a},
\end{gathered}
$$


where $s_{t}^{a}$ is savings and $R_{t+1}^{K}$ is the gross rate of return on capital between periods $t$ and $t+1$.

Solving this optimization problem gives

$$
s_{t}^{a}=\sigma \max \left[\left(a_{t}-\mu\right) w_{t}^{S}, w_{t}^{U}\right],
$$

where $\sigma=1 /(2+\rho)$ is the marginal propensity to save.

\subsection{Final Good}

The final good is produced by a continuum of unit mass competitive firms indexed by $i \in(0,1)$. Production requires the use of unskilled labor, $N_{t}^{U, i}$, capital, $K_{t}^{i}$, and a DixitStiglitz combination of a continuum of intermediate inputs, $x_{j, t}^{i}$, where $j \in\left(0, M_{t}\right){ }^{8}$

The production function of firm $i$ takes the form

$$
Y_{t}^{i}=\Xi_{t}\left(K_{t}^{i}\right)^{\alpha}\left(N_{t}^{U, i}\right)^{\beta}\left[\int_{0}^{M_{t}}\left(x_{j, t}^{i}\right)^{\eta} d j\right]^{(1-\alpha-\beta) / \eta},
$$

where $\alpha, \beta, \eta \in(0,1), \alpha+\beta<1$, and $1 /(1-\eta)>1$ is (the absolute value of) the price elasticity of demand for each intermediate good, and $\Xi_{t}$ a productivity factor. Constant returns prevail in all inputs.

As a result of an Arrow-Romer type externality, productivity depends on the (adjusted) capital-labor ratio:

$$
\Xi_{t}=\left(\frac{K_{t}^{v}}{N_{t}^{U}}\right)^{\beta}
$$

where $v>0, K_{t}=\int_{0}^{1} K_{t}^{i} d i$ is the aggregate capital stock and $N_{t}^{U}=\int_{0}^{1} N_{t}^{U, i} d i$ is total employment in manufacturing.

For simplicity, firms in the manufacturing sector do not face financing constraints. With the price of the final good normalized to unity, and assuming for simplicity full depreciation of capital, profits of manufacturing firm $i, \Pi_{t}^{Y, i}$, are given by

$$
\Pi_{t}^{Y, i}=Y_{t}^{i}-\int_{0}^{M_{t}} p_{t}^{j} x_{j, t}^{i} d j-w_{t}^{U} N_{t}^{U, i}-R_{t}^{K} K_{t}^{i},
$$

where $p_{t}^{j}$ is the price of intermediate good $j$.

\footnotetext{
${ }^{8}$ The analysis could be extended to account for the fact that skilled labor is also used in the production of the final good. This would, however, significantly complicate the analysis without adding much insight.
} 
Each producer maximizes profits subject to (10) with respect to private inputs, labor, capital, and quantities of all intermediate goods $x_{j, t}^{i}, \forall j$, taking factor prices and $M_{t}$ as given. This yields

$$
\begin{gathered}
R_{t}^{K}=\frac{\alpha Y_{t}^{i}}{K_{t}^{i}}, \quad w_{t}^{U}=\frac{\beta Y_{t}^{i}}{N_{t}^{U, i}}, \\
x_{j, t}^{i}=\left(\frac{\gamma Z_{t}^{i}}{p_{t}^{j}}\right)^{1 /(1-\eta)}, \quad j=1, \ldots M_{t},
\end{gathered}
$$

where $\gamma=1-\alpha-\beta$ and

$$
Z_{t}^{i}=Y_{t}^{i} / \int_{0}^{M_{t}}\left(x_{j, t}^{i}\right)^{\eta} d j
$$

Each firm demands the same amount of each intermediate input, Equation (13) therefore implies that the aggregate demand for intermediate input $j$ is

$$
x_{j, t}=\int_{0}^{1} x_{j, t}^{i} d i=\int_{0}^{1}\left(\frac{\gamma Z_{t}^{i}}{p_{t}^{j}}\right)^{1 /(1-\eta)} d i .
$$

Because all firms producing the final good areidentieal and their number is normalized to unity, $K_{t}^{i}=K_{t}, Z_{t}^{i}=Z_{t}, \forall i$, and the total demand for intermediate inputs is the same across firms, $x_{t}^{i}=x_{t}, \forall i$. Moreover, in a symmetric equilibrium, $x_{j, t}^{i}=x_{t}^{i}, \forall j$. Thus, $\int_{0}^{1}\left[\int_{0}^{M_{t}}\left(x_{j, t}^{i}\right)^{\eta} d j\right] d i=M_{t} x_{t}^{\eta}$. Using these results, equations (10) and (11) imply that aggregate output of the final good is

$$
Y_{t}=\int_{0}^{1} Y_{t}^{i} d i=K_{t}^{\alpha+v \beta} M_{t}^{\gamma / \eta} x_{t}^{\gamma}
$$

To ensure steady-state growth, we impose $\alpha+v \beta+\gamma / \eta=1$. This condition is equivalent to an implicit restriction on the magnitude of the productivity effect of aggregate capital, $v$. Note that it also implies that $\gamma<\eta$, a condition that is used later.

Under this condition,

$$
Y_{t}=m_{t}^{\gamma / \eta} x_{t}^{\gamma} K_{t}
$$

where $m_{t}=M_{t} / K_{t}$ is the (disembodied) knowledge-capital ratio.

\subsection{Intermediate Goods}

Firms in the intermediate sector (identified with superscript $I$ ) are monopolistically competitive. There is only one producer of each input $j$, and each of them must pay a 
fee (a patent) to use the blueprint for that input created in the design sector (identified with superscript $R$ ). Production of each unit of an intermediate good $j$ requires a single unit of the final good; the marginal cost of producing $j$ is thus one.

Once the fee involved in purchasing a patent has been paid, each intermediate good producer sets its price to maximize profits, $\Pi_{j, t}^{I}$, given the perceived demand function for its good (which determines marginal revenue), $x_{j, t}$ :

$$
\Pi_{j, t}^{I}=\left(p_{t}^{j}-1\right) x_{j, t} .
$$

Substituting (15) in this expression and imposing $Z_{t}^{i}=Z_{t}, \forall i$, yields

$$
\Pi_{j, t}^{I}=\left(p_{t}^{j}-1\right)\left(\frac{\gamma Z_{t}}{p_{t}^{j}}\right)^{1 /(1-\eta)}
$$

Maximizing this expression with respect to $p_{t}^{j}$, taking $Z_{t}$ as given, yields the optimal price as

$$
p_{t}^{j}=p_{t}=\eta^{-1}, \forall j
$$

which implies, using (15), that the optimal quantity of each intermediate input demanded by producers of the final good is

$$
x_{j, t}=x_{t}=\left(\gamma \eta Z_{t}\right)^{1 /(1-\eta)} . \quad \forall j
$$

From the definition of $Z_{t}^{i}$ in $(14)$, in a symmetric equilibrium $Z_{t}=Y_{t} / M_{t} x_{t}^{\eta}$. Substituting this expression in (19) yields

$$
x_{t}=\gamma \eta\left(\frac{Y_{t}}{M_{t}}\right)
$$

Substituting) (18) and (20) in (17) yields the maximum profit for an intermediateinput producer:

$$
\Pi_{t}^{I}=(1-\eta) \gamma\left(\frac{Y_{t}}{M_{t}}\right) .
$$

whieh is the standard expression obtained in Romer-type innovation models.

For simplicity, we assume that intermediate-input producing firms last only one period, and that patents are auctioned off randomly to a new group of firms in each period. Thus, each producer of a new intermediate good holds a patent only for the 
period during which it is bought, implying monopoly profits during that period only; yet patents last forever. ${ }^{9}$ By arbitrage, therefore, the patent price $p_{t}^{R}$ is

$$
p_{t}^{R}=\Pi_{t}^{I} .
$$

\subsection{Design Sector}

The outcome of a successful research activity is a design, or blueprint, for the production of a new intermediate good. Firms do not have access to a technology that allows them to observe the level of effort expended by each researcher; they therefore cannot condition wages on individual productivity.

Let $q_{t} \in(0,1)$ denote the probability of success of a design activity. In a symmetric equilibrium, $q_{t}$ is independent across designers and is therefore the same for all projects. The (expected) flow of new designs is given by

$$
M_{t+1}-M_{t}=q_{t} A_{t}\left(\frac{N_{t}^{S}}{N}\right),
$$

where $A_{t}$ is a productivity factor, common to all firms engaged in design activities. In addition, as in Dinopoulos and Thompson (2000), we also account for a dilution effect, which captures the fact that creating new designs becomes more difficult as the size of the market, measured by the size of the adult population, $N$, increases.

In standard fashion, productivity itself is linearly related to the existing stock of designs, to capture a standing-on-shoulders effect: ${ }^{10}$

$$
A_{t}=M_{t}
$$

Designers have no wealth and must turn to external finance to cover production costs. The outcome of a research activity, however, is private information: only the

\footnotetext{
${ }^{9}$ It could be assumed instead that firms last forever and that patents last for one period only, which would imply that intermediate good producers make zero profits thereafter. However, this would require distinguishing between the price charged by monopolists for new goods produced at $t$, and the price charged by competitive firms for goods produced before $t$. This would complicate the solution of the model without providing much insight, given the issue at stake. See Agénor and Canuto (2015) for a more detailed discussion.

${ }^{10} \mathrm{As}$ in Agénor and Canuto (2015), it could be assumed that there are increasing returns to the diffusion of ideas, at least in a certain range. However, in the present case this would not add much to the main argument.
} 
designer can directly observe whether an activity has been successful, whereas lenders must spend resources on acquiring that information. To do so requires recourse to a costly monitoring technology.

As discussed next, each designer borrows from a financial intermediary, at the gross interest rate $R_{t}^{L}$, to cover wage costs. Assuming that loan repayments are contingent on the design project being successful (a consequence of limited liability, as discussed next), profits can be defined as $p_{t}^{R}\left(M_{t+1}-M_{t}\right)-q_{t} w_{t}^{S} R_{t}^{L} N_{t}^{S}$. The zero-profit condition implied by free entry is thus

$$
w_{t}^{S} R_{t}^{L}=\frac{p_{t}^{R} A_{t}}{N}
$$

which equates wage costs (inclusive of borrowing costs) with the return to innovation. Due to limited liability, this condition does not depend directly on $q_{t}$.

\subsection{Financial Intermediation}

Financial intermediation takes place solely between designers and lenders, under a regime of uncollateralized lending and limited liability; in case of default, lenders cannot recover any of their funds and no penalty can be imposed on borrowers. There exists a large number of lenders who compete in the provision of financial services. Each lender has access to a source of (domestic or foreign) funding at the exogenous gross rate $R^{W}$. There is no risk of bankruptcy because they hold a perfectly diversified portfolio of loan contracts. As noted earlier, designers have no funds of their own to invest in their projects and therefore have to obtain external financing. Because of the limited liability constraint, a potential problem of moral hazard naturally emerges.

The funds needed for each research project are provided by lenders who are endowed with a monitoring technology. As in Besanko and Kanatas (1993) and Morales (2003), the monitoring technology allows lenders to increase the effort of the designer; the intensity with which the lender monitors the designer who borrowed from him (her) determines the additional effort that the former can force the latter to exert. We also assume that there is a one-to-one relationship between individual effort and the probability of success of the research project. ${ }^{11}$ As a result, the monitoring services of

\footnotetext{
${ }^{11}$ Thus, although the probability of success does not depend directly on innate ability, it is con-
} 
the lenders play an important role in determining productivity (and thus the capacity to innovate) in the design sector.

Consider a research project that requires using one worker, at the wage $w_{t}^{S} \cdot{ }^{12}$ If successful, an event that occurs with probability $q_{t}$, the project yields a return $p_{t}^{R}$, the price of the patent that is eventually acquired. The designer obtains the funds from a lender and in exchange pays in case of success an amount $R_{t}^{L} w_{t}^{S}$, where $R_{t}^{L}>R_{t}^{K}$ is an interest factor, and (as a result of the limited liability constraint) nothing otherwise. ${ }^{13}$ The expected profit of the designer is thus given by

$$
\Pi_{t}^{D}=q_{t}\left(p_{t}^{R}-R_{t}^{L} w_{t}^{S}\right) .
$$

If the designer is not monitored at all, the level of effort he would exert, and thus the probability of success of the project, is $q_{m}$, which we take to be constant for simplicity. This no-monitoring level of effort is implementable at no cost for the lender. However, if the lender wishes to impose a higher level of effort, he faces a monitoring cost $m c()$ that is positively and linearly related to the amount lent, and increasing and convex in the difference between the desired level of effort and $q_{m}$ :

$$
m c\left(q_{t}-q_{m} ; w_{t}^{S}\right)=\frac{\chi\left(q_{t}-q_{m}\right)^{2}}{2} w_{t}^{S},
$$

where $\chi>0$ will be interpreted in what follows as a measure of the intensity of monitoring costs per project on, equivalently, the degree of credit market imperfections. We assume for the moment that $\chi$ is constant, but as shown later, its endogeneity is crucial to determining the existence of multiple steady states.

By implication, the expected profit (per borrower) of the lender is given by

$$
\Pi_{t}^{L}=q_{t} R_{t}^{L} w_{t}^{S}-\left\{R^{W}+\frac{\chi\left(q_{t}-q_{m}\right)^{2}}{2}\right\} w_{t}^{S},
$$

which shows that, for $R_{t}^{L}$ given, an increase in the probability of success $q_{t}$ has two conflicting effects on expected profits: on the one hand, it raises the (expected) payoff for the lender, but on the other it raises monitoring costs.

ditional on effort, which can vary independently of ability. However, and crucially for the analysis, effort is observable by creditors.

${ }^{12}$ In principle, as noted earlier, each worker in the design sector works for only $1-\varepsilon$ of his time; we abstract from this to avoid cluttering needlessly the expressions derived in this section.

${ }^{13}$ To avoid a corner solution, we assume that the optimal payment, $R_{t}^{L} w_{t}^{S}$, cannot exceed the designer's return, $p_{t}^{R}$. 
As noted earlier, lenders compete among themselves for the provision of loans. By choosing one of them, and thus how much monitoring is exerted on his activities, a designer essentially determines the probability of success of his project. However, for simplicity we assume that once the researcher chooses a lender to finance his project, he cannot renege on the terms of the contract and seek another source of finance.

The equilibrium in the credit market follows from a three-stage process. ${ }^{14}$ In the first stage, lenders choose the level of monitoring services that they want to provide, taking as given the return on loans and under the assumption that the borrower is "locked" into the contract. This, equivalently, determines the probability of success of the projects that they choose to finance. In the second stage, each designer chooses a lender on the basis of the level of monitoring services offered. Once that choice is made, but not before, the designer is tied with the lender and cannot walk away from the contract. In the third and final stage, the equilibrium payment to be imposed on the designer in case of success (that is, the gross lending rate) is determined through a zero-profit condition.

In the first stage the lender sets the level of effort that he wants (or equivalently the probability of success), so as to maximize profits, taking as given the return on loans. Setting $d \Pi_{t}^{L} / d q_{t}=0$ in (28) yields the first-order condition

$$
R_{t}^{L}=\chi\left(q_{t}-q_{m}\right)
$$

which simply equates the marginal benefit, $R_{t}^{L}$, to the marginal cost of monitoring, $\chi\left(q_{t}-q_{m}\right)$. Rearranging this equation gives the equilibrium probability of success as

$$
q_{t}=q_{m}+\frac{R_{t}^{L}}{\chi},
$$

which implies (assuming that the solution is admissible) that an increase in the return on loans raises the amount of monitoring that lenders find optimal to engage in. Note also that, for $R_{t}^{L}$ given, the higher the degree of credit market imperfections (the higher $\chi$ is), the smaller the probability of success. Put differently, if the (marginal) cost of

\footnotetext{
${ }^{14}$ In Morales (2003), the equilibrium of the credit market is also solved through a three-stage process, but this is done backward. In the present setting, there is no advantage in doing so given how the model is solved, and we therefore proceed with a forward sequence.
} 
monitoring increases, lenders will do less of it, therefore reducing the likelihood of success.

Substituting (29) in (26) gives $\Pi_{t}^{D}=q_{t}\left[p_{t}^{R}-\chi\left(q_{t}-q_{m}\right) w_{t}^{S}\right]$; taking $p_{t}^{R}$ and $w_{t}^{S}$ as given, expected profits of the designer are increasing in $q_{t}$ if $\chi$ is sufficiently low. In such conditions, the contract makes monitoring desirable for him as well, because it will reduce the lender's share in the project's return and increase the probability that the project succeeds. Consequently, as long as $d \Pi_{t}^{D} / d q_{t}>0$, in the second stage designers will choose the lender that offers the highest level of monitoring services.

In the third stage, competition among lenders in the provision of monitoring services ensures that the equilibrium level of expected profits for each lender is zero. Put differently, the gross return on loans will be the highest value of $R_{t}^{L}$ that implies zero expected profits for lenders, that is, from (28),

$$
q_{t} R_{t}^{L}-R^{W}-\frac{\chi\left(q_{t}-q_{m}\right)^{2}}{2}=0
$$

which can be rearranged to give

$$
R_{t}^{L}=\frac{R^{W}+0.5 \chi\left(q_{t}-q_{m}\right)^{2}}{q_{t}} .
$$

As shown in the Apppendix, combining (30) and (31), and using the implicit function theorem, it can be established that an increase in $\chi$ raises in general the interest rate on loans. From (25), a higher loan rate tends to reduce the skilled wage in the design sector, and therefore mitigates incentives to acquire skills. Thus, credit market imperfections, which limit access to finance, not only tend to reduce activity in the design sector directly (by making it more costly), they tend also to affect it indirectly-by reducing the supply of skilled individuals.

In addition, as also shown in the Appendix, an increase in $\chi$ has in general an ambiguous effect on the probability of success. On the one hand, a higher $\chi$ increases the return on loans and raises the amount of monitoring, but on the other, it increases the marginal cost of monitoring. In what follows we will focus on the more plausible case where the second (direct) effect dominates, implying that an increase in the monitoring cost lowers the probability of success $(d q / d \chi<0)$. 
With full depreciation, as noted earlier, closing the model requires that the capital stock in $t+1$ be equal to savings in period $t$ :

$$
K_{t+1}=s_{t}^{U} N_{t}^{U}+s_{t}^{S} N_{t}^{S}
$$

or equivalently

$$
K_{t+1}=\sigma\left(w_{t}^{U} N_{t}^{U}+w_{t}^{S} N_{t}^{S}\right) .
$$

Thus, despite agents earning heterogeneous wages, because they all have the same logarithmic utility function aggregate savings is equal to a constant fraction $\sigma$ of the economy's wage bill.

\section{Equilibrium}

In this economy an equilibrium with imperfect competition is a sequence of consumption and saving allocations $\left\{c_{t}^{h, t}, c_{t+1}^{h, t}, s_{t}^{h}\right\}_{t=0}^{\infty}$, for $h=U, S$, capital stock $\left\{K_{t}\right\}_{t=0}^{\infty}$, prices of production inputs $\left\{w_{t}^{U}, w_{t}^{S}, r_{t+1}^{K}\right\}_{t=0}^{\infty}$, prices and quantities of intermediate inputs $\left\{p_{t}^{j}, x_{j, t}\right\}_{t=0}^{\infty}, \forall j \in\left(0, M_{t}\right)$, existing varieties, $\left\{M_{t}\right\}_{t=0}^{\infty}$, such that, given initial stocks $K_{0}>0$, and $M_{0}>0$,

a) individuals working in manufacturing and the design sector maximize utility by choosing consumption subject to their intertemporal budget constraint, taking factor prices and the tax rate as given,

b) firms in the final good sector maximize profits by choosing labor, capital, and intermediate inputs, taking input prices as given;

c) intermediate input producers set prices so as to maximize profits, while internalizing the effect of their decisions on the perceived aggregate demand curve for their product;

d) producers in the design sector maximize profits by choosing labor, taking wages, patent prices, productivity, monitoring costs, and population, as given;

e) the equilibrium price of each blueprint extracts all profits made by the corresponding intermediate input producer;

f) zero profits hold in the credit market; and

g) all markets clear. 
A balanced growth equilibrium is an equilibrium with imperfect competition in which

a) $\left\{c_{t}^{h, t}, c_{t+1}^{h, t}, s_{t}^{h}\right\}_{t=0}^{\infty}$, for $h=U, S$, and $K_{t}, Y_{t}, M_{t}, w_{t}^{U}, w_{t}^{S}$, grow at the constant, endogenous rate $1+g$, implying that the knowledge-capital ratio is also constant;

b) the rate of return on capital $R_{t+1}^{K}$ is constant;

$c$ ) the price of intermediate goods $p_{t}$ and the patent price $p_{t}^{R}$ are constant;

d) the probability of success in the design sector is constant; and

e) the threshold level of ability below which individuals choose to remain unskilled, $a_{t}^{C}$, and thus work in manufacturing, is constant. By implication, the fraction of the labor force employed in the design sector is also constant.

As shown earlier (equation (1)), the threshold level of ability $a_{t}^{C}$ depends on the wage ratio, $w_{t}^{U} / w_{t}^{S}$. In the Appendix the wage ratio is shown to be given by

$$
\frac{w_{t}^{S}}{w_{t}^{U}}=\frac{(1-\eta) \gamma}{\beta R_{t}^{L}} a_{t}^{C}
$$

Substituting (33) in (1) and setting $\mu=0$ for simplicity yields

$$
a_{t}^{C}=G\left(R_{t}^{L}\right)=\left[\frac{\beta R_{t}^{L}}{(1-\eta) \gamma}\right]^{0.5}
$$

where $G^{\prime}>0$, implying therefore a linear and increasing relationship between $a_{t}^{C}$ and $R_{t}^{L} .^{15}$ Thus, a higher cost of loans (or, equivalently, a lower probability of success) raises the proportion of unskilled workers.

Combining (30) and (31), as noted earlier, yields a solution that relates $R_{t}^{L}$ positively to $\chi$. The interest rate, and by implication the ability threshold, are thus constant as long às $\chi$ itself is constant.

The Appendix also shows that the fundamental dynamic equation of the system is

$$
m_{t+1}=\Phi\left(m_{t}\right)=\frac{\Lambda^{-1}\left\{1+q 0.5\left[1-G\left(R^{L}\right)^{2}\right]\right\}}{\sigma\left[\beta+\left(R^{L}\right)^{-1} \Omega\left[1-G\left(R^{L}\right)^{2}\right]\right.} m_{t}^{\left(1-\gamma \eta^{-1}\right) /(1-\gamma)}
$$

where $\Lambda=(\gamma \eta)^{\gamma /(1-\gamma)}$ and $\Omega=0.5(1-\eta) \gamma$.

The condition for stability of $(35)$ is $\left|\left(1-\gamma \eta^{-1}\right) /(1-\gamma)\right|<1$, or equivalently $1-$ $\gamma \eta^{-1}<1-\gamma$. This condition boils down to $\eta<1$, which is always satisfied. Thus, with both the interest rate on loans $R^{L}$ and the probability of success $q$ constant, there is a

\footnotetext{
${ }^{15}$ As noted in the Appendix, a similar relationship holds between $a_{t}^{C}$ and $R_{t}^{L}$ when $\mu>0$.
} 
single equilibrium. If, in addition, $\eta>\gamma$, as one would expect in practice, convergence occurs without oscillations.

From the results in the Appendix, the steady-state growth rate is given by

$$
1+g=\Lambda m^{\gamma\left(\eta^{-1}-1\right) /(1-\gamma)} \sigma\left\{\beta+\Omega \frac{\left[1-G\left(R^{L}\right)^{2}\right]}{R^{L}}\right\}
$$

where $m$ is the steady-state solution of (35), given by

$$
m=\left\{\frac{\Lambda^{-1}\left\{1+q 0.5\left[1-G\left(R^{L}\right)^{2}\right]\right\}}{\sigma\left[\beta+\left(R^{L}\right)^{-1} \Omega\left[1-G\left(R^{L}\right)^{2}\right]\right.}\right\}^{\varkappa},
$$

and $\varkappa=1 /\left[1-\left(1-\gamma \eta^{-1}\right) /(1-\gamma)\right]>0$.

Equations (36) and (37) show that the economy's steady-state growth rate depends on the cost of borrowing both directly, through its effect on activity in the design sector, and indirectly, through its impact on relative wages and labor supply. From (37), it can be shown that $d m / d \chi$ is in general ambiguous. On the one hand, an increase in the unit cost of monitoring raises the cost of loans $\left(d R^{L} / d \chi>0\right)$, which lowers wages, savings, and the capital stock. On the other, it leads to a reduction in effort, which lowers the probability of success $(d q / d \chi<0)$ and activity in the design sector. The first effect tends to increase the knowledge-capital ratio, whereas the second tends to lower it. This ambiguity exists even if there is no labor supply effect, that is, even if $a^{C}$ is constant. In addition, when $a^{C}$ is endogenous, the fall in the skilled wage raises the threshold value $a^{C}$ which tends to lower the share of skilled workers in the economy - thereby further reducing both activity in the design sector and aggregate savings and thus the capital stock. By implication, from (36), the impact of a higher $\chi$ on the steady-state growth rate is in general ambiguous, so that $d(1+g) / d \chi \lessgtr 0$. However, it can alsø be established that if $d m / d \chi<0$, then $d(1+g) / d \chi<0$ as well. ${ }^{16}$ This result is useful in what follows.

\section{Multiple Steady States}

In the foregoing discussion, it was assumed that the intensity of monitoring costs per research project, as measured by $\chi$, is constant. Suppose now instead that although $\chi$

\footnotetext{
${ }^{16}$ Suppose indeed that $\eta>\gamma$; thus, $\left(1-\gamma \eta^{-1}\right) /(1-\gamma)>0$. Given that $G^{\prime}>0, d R^{L} / d \chi>0$, and $1-G\left(R^{L}\right)^{2}>0$, we have $\operatorname{sg}\left[d\left\{\left[1-G(R)^{2}\right] / R^{L}\right\} / d \chi\right]=\operatorname{sg}\left\{-2 R^{L} G^{\prime}-\left[1-G\left(R^{L}\right)^{2}\right]\right\}<0$. Suppose also that $d m / d \chi<0$; then, from $(36), d(1+g) / d \chi<0$.
} 
is taken as given at the level of each individual lender when taking its decisions, it falls with the aggregate number of successful projects, scaled by the size of the economy (as measured by the capital stock). Thus, the decision rules derived earlier remain the same, but in equilibrium $\chi_{t}=\chi\left(m_{t}\right)$, with $\chi^{\prime}<0$. In addition, suppose that this relationship is concave $\left(\chi^{\prime \prime}>0\right)$ and holds only for $\chi \in\left(\chi_{m}, \chi_{M}\right)$, where $\chi_{m}>0$ and $\chi_{M}>\chi_{m}$. Intuitively, lenders all learn from financing successful projects and this translates into an across-the-board reduction in monitoring costs at the aggregate level-but at a decreasing rate and only up to a certain point, $\chi_{m}$, which represents an incompressible cost (collecting basic information, acquiring and using computer equipment to keep track of financial performance, and so on). A possible reason for this negative relationship is that, in the tradition of Schumpeter (1961), by evaluating profitable (and eventually successful) projects, financial intermediaries as a group help to lower information costs - thereby reducing, at least initially, the cost of screening and monitoring future borrowers. Alternatively, as in Blackburn and Hung (1998) and Harrison et al. (1999) for instance, it could be assumed that an increase in the number of (successful) projects induces more lenders to enter the market; in turn, higher entry reduces the average distance between financial intermediaries and borrowers, promotes regional specialization, and lowers the cost of screening and monitoring - again, at least in a first stage. ${ }^{17}$

A highly stylized yet plausible specification that captures the equilibrium relationship between $\chi_{t}$ and $m_{t}$ is

$$
\chi_{t}=\max \left(\chi_{M}-A m_{t}^{v}, \chi_{m}\right)
$$

where $A>0$ and $v \in(0,1)$. Thus, unit monitoring costs fall continuously from $\chi_{M}$ as $m_{t}$ increases and remain constant at the incompressible level $\chi_{m}$ once $m_{t}$ reaches the critical value

$$
m_{H}=\left(\frac{\chi_{M}-\chi_{m}}{A}\right)^{1 / v}
$$

As before, although lenders choose the level of monitoring effort, they take the

\footnotetext{
${ }^{17}$ In principle, lenders could also learn from financing eventually unsuccessful projects. However, as long as they learn more from successful projects, our results would not be qualitatively affected. Note also that a learning process (implying persistence in $\chi_{t}$ ) could be introduced, but this would not affect qualitatively our results.
} 
monitoring cost per project (which depends on an aggregate quantity) as given. From equations (37) and (38), the steady-state knowledge-capital ratio $m$ depends again on the monitoring cost parameter, through its direct effect on the cost of loans and the probability of success, $R^{L}$ and $q$, from (30) and (31). However, in contrast to the case considered previously, the endogeneity of $\chi$ means that multiple steady states may occur.

This possibility is illustrated in Figure 1, in $m-\chi$ space. Curve $M M$ corresponds to the steady-state solution (37), and $C C$, which is shown in red for convenience, corresponds to equation (38). The slope of $M M$ depends on the sign of $d m / d \chi$, which (as shown earlier) is in general ambiguous. If $M M$ is positively sloped, multiple steady states cannot occur. However, if it is negatively sloped multiple steady states may emerge, depending on where the curves intersect. Figure 1 illustrates the case where $M M$ is decreasing and concave. In Panel $\mathrm{A}, M M$ and $C C$ intersect only once; there is a single equilibrium, corresponding to the point of tangency of the two curves. In Panel $\mathrm{B}$, the curves intersect twice, at $E$ and $E^{\prime}$. For stability, curve $M M$ must cut curve $C C$ from above; this is always the case, for instance, when $v=0$, in which case $C C$ is a flat curve. Thus, point $E$ is an unstable equilibrium, whereas point $E^{\prime}$ is stable. However, because $E$ is unstable, if the economy starts away from it, it cannot converge to it. To the left of point $m_{E}$ (the value of $m$ corresponding to the equilibrium point $E$ ), a degenerate solution with an ever-increasing unit monitoring cost would obtain, whereas to the right of $m_{E}$ the economy would always converge to the stable equilibrium. But at most, only two equilibria may exist. ${ }^{18}$

Figure 2 considers the case where $M M$ is again decreasing but convex. Based on numerical simulations, this appears to be the most likely case. ${ }^{19}$ Results similar to ${ }^{18}$ Because $\chi_{t}$ is monotonically decreasing in $m_{t}$, the only case where a single equilibrium exists is
the case depicted in Panel A. Note also that if $M M$ could take a more complicated concave-convex-
concave shape, then three equilibria could emerge. However, numerical experiments, as discussed
later, suggest that this is a rather unlikely scenario.
${ }^{19}$ Initial simulations were conducted with time allocated to schooling $\varepsilon=0.15$, a training cost
$\mu=0.05$ of the skilled wage, a propensity to save $\sigma=0.12$, an elasticity of output with respect to
capital $\alpha=0.3$, an elasticity of output with respect to unskilled labor $\beta=0.6$ (implying therefore
an elasticity of output with respect to intermediate inputs of $\gamma=0.1$ ), an elasticity of substitution
between intermediate inputs $\eta=0.6$, an autonomous probability of project success $q_{m}=0.1$, and
a unit monitoring cost initially at $\chi=4.0$. Parameter values for $\alpha$ and $\beta$ for instance are fairly
standard, whereas the value of $\varepsilon$ represents about 4 years of college if adulthood corresponds to 25 
those obtained previously can again be derived, depending on the degree of convexity. In Panel $\mathrm{A}$, there is a single equilibrium, whereas in Panel $\mathrm{B}$, there are two equilibria, $E$ and $E^{\prime}$. As in Figure 1, point $E$ is unstable whereas point $E^{\prime}$ is stable. However, it is now also possible to obtain three equilibria, as shown in Panel $\mathrm{C}$, where $M M$ and $C C$ intersect three times. In that case, both $E^{\prime}$ and $E^{\prime \prime}$ are stable, whereas $E$ is unstable. The equilibrium at point $E^{\prime \prime}$, which is characterized by low steady-state activity in the design sector (low $m$ ) and high unit monitoring costs (high $\chi$ ), and therefore low steady-state growth, corresponds to what we may call a middle-income trap. If the economy starts with a value of $m$ located below $m_{E}$ (the knowledge-capital ratio corresponding again to the unstable equilibrium) it will always converge to the trap and will remain stuck there when it reaches it.

What is the role of public policy in this setting? Consider the case where the initial position of the economy is indeed at point $E^{\prime \prime}$, which corresponds to a middle-income trap with high monitoring costs and a low knowledge-capital ratio. Suppose now that the government can implement a budget-neutral policy such as the creation of credit bureaus, which help to collect, analyze, and disseminate information about borrowers to potential lenders - what Laeven et al. (2015) refer to as financial innovation. Suppose also that this policy enhances the screening and monitoring ability of financial intermediaries, and that it translates into a reduction in the threshold value $\chi_{m}$ in (38) as well as an increase in $A$, which implies a faster marginal reduction in monitoring costs when innovation activity expands. Graphically, this leads to a downward shift and clockwise tilt in $C C$ (which therefore becomes steeper), as shown by the dotted curve in Panel D in Figure 2. ${ }^{20}$ Thus, as long as $\chi>\chi_{m}$, the intensity of monitoring costs falls now at a faster rate with increases in $m$, and eventually settles at a lower level than before.

Moreover, starting at point $E^{\prime \prime}$, the shift in $C C$ may be large enough for the new point of intersection with $M M$ to be at Point $B$, where only a unique equilibrium remains, with a lower $\chi$ and a higher $m$. The policy shift will therefore induce on

years. Subsequent experiments with a number of different values did not alter the results.

${ }^{20}$ As can be inferred from (39), a higher $A$ tends to lower the threshold $m_{H}$, whereas a lower $\chi_{m}$ tends to increase it. The figure assumes that the net effect is a reduction in $m_{H}$. The main point of the analysis would also hold if instead $m_{H}$ were to increase or to remain constant. 
impact a downward vertical movement from $E^{\prime \prime}$ to a point on the new $C C$ curve. From there, the economy will evolve gradually toward Point $B$, with a transition process characterized by increases in the knowledge-capital ratio and further reductions in unit monitoring costs. ${ }^{21}$ The new equilibrium is characterized also by a larger share of skilled workers in the population, higher growth, and higher productivity in the design sector. Put differently, a forceful policy that makes it easier for innovators to secure financing for their projects may allow a country to escape from the middle-income trap, by putting its economy on a path that will eventually lead to a high-skill, highinnovation, and high-growth equilibrium.

\section{$6 \quad$ Policy Implications}

As noted in the introduction, a number of observers have argued that financial market imperfections, especially those associated with-information asymmetries and transaction costs, are likely to be especially binding on talented individuals and small enterprises that lack collateral, credit histories, and connections. Indeed, it may be more difficult for small and newer firms, eompared to larger and more established firms, to either raise outside finance (due to moresevere problems of information asymmetries) or secure internal funds for the financing of innovation projects. As pointed out by the Inter-American Development Bank (2010) for instance, lack of finance - in addition to small domestic markets, and a shortage of trained personnel-is one of the key obstacles to innovation in Latin America. At the same time, although a country like Korea has succeeded mainly because the R\&D activities of its largest and most competitive conglomerates were financed internally or through captive funds - in becoming an innovation-based economy without highly developed venture capital markets, arguably it could have performed even better if its small and medium-size innovative firms had not faced severe financial constraints.

The foregoing analysis contributes to this debate in an important way. It suggests

\footnotetext{
${ }^{21}$ Of course, the steeper the new $C C$ curve is, the larger the southeast movement in point $B$. Visual inspection of Panel D also suggests that with no change in the slope parameter $A$ and a drop only in $\chi_{m}$, the downward-sloping portion of $C C$ could also shift in such a way as to achieve a single equilibrium.
} 
that access (or lack thereof) to finance may constrain growth not only by increasing the cost of monitoring innovation activities, as emphasized in other contributions such as Blackburn and Hung (1998), Morales (2003), Aghion et al. (2005), and Aghion and Howitt (2009), but also by indirectly altering incentives to acquire skills. This matters because the degree to which firms innovate and the distribution of skills among workers (which conditions the development of innovation activities) are jointly determined; lack of skills and poor access to finance are interrelated. ${ }^{22}$ In addition, credit market imperfections may lead to the emergence of multiple steady states, one of them corresponding to a middle-income trap. Yet, at the same time, public policy is not powerless - forceful measures aimed at mitigating the impact of these imperfections (or,) more specifically, those aimed at reducing the unit cost of monitoring R\&D projects) may allow a country to escape from that trap. As we define it here, the middle-income growth trap is consistent with the evidence on the high cost of financial intermediation in developing countries in general, and middle-income countries in particular (see for instance World Bank (2008)). It is also consistent with the fact that those among these countries that have experienced a significant and sustained slowdown in growth are often characterized by insufficient labor quality and limited R\&D activity. But to a significant extent, the characteristics of the middle-income trap, as highlighted here, could equally apply to some high-income OECD countries where growth has remained anemic for significant periods of time, and promoting innovation remains a key policy challenge.

The broader policy lessons of our analysis are indeed consistent with the recent evidence (reviewed in Section 2) for both industrial and developing countries suggesting that financial constraints may be a key factor behind low innovation performance. If new entrants and startup firms are the most affected by the lack of finance, it may be important for governments to provide some form of direct assistance to these firms. Such measures include direct $R \& D$ funding, tax incentives for $R \& D$, as well as support for innovation-related collaboration across firms and between universities/labs and firms (see OECD (2010), Lilischkis (2011), and LSE Growth Commission (2013)). Ensuring access to more funding sources may lead to more intensive innovation, more

\footnotetext{
${ }^{22}$ Attitude toward risk matters as well; to turn a promising idea into a new firm, researchers must also face the right incentives to give up safe employment for a risky entrepreneurial career.
} 
successful R\&D projects which, in turn, may result in lower unit monitoring costs, thereby helping to further promote financial intermediation, innovation, and economic growth. ${ }^{23}$ However, our analysis also suggests that, rather than providing direct subsidies, an alternative policy would be to implement measures that are aimed directly at mitigating asymmetric information problems and reducing unit monitoring costs, such as for instance the creation of credit bureaus or registries that help to collect, analyze, and disseminate information about potential borrowers to lenders. The evidence suggests, for instance, that more effective credit information sharing is associated with greater availability and lower cost of bank loans to firms (World Bank (2014, Chapter $3)$ ). Such a policy may actually be more effective in middle-income countries, given a weak institutional environment and the practical difficulties that may arise in selecting research projects whose outcomes are inherently uncértain.

Our analysis also points out that improved access to finance for innovative firms has side benefits - it may improve incentives to acquire skills, and therefore indirectly help to promote innovative research. At the same time, however, it is important to realize that in practice a strategy of promoting the financial sector across the board may not yield only benefits. The reason is that it could lead to a misallocation of talent, as discussed elsewhere in the literature (see, for instance, Ang (2011) and Agénor and Canuto (2015)). Indeed, if the expansion of the financial sector, by offering higher earnings and rewards, draws toomany talented individuals, it could hamper in the long run the development of the innovation sector. Thus, rather than promoting finance in general, what is needed is a well-targeted policy aimed at making it easier for innovative firms to secure adequate funding for their activity.

\section{Concluding Remarks}

The purpose of this paper was to study interactions between access (or lack thereof) to finance, product innovation, and labor supply in a growing economy. To do so we

\footnotetext{
${ }^{23}$ The fact that in practice the importance of financial constraints may vary with firm characteristics points also to another conclusion: for any innovation policy program to be effective it is vital not to rely on uniform R\&D and innovation support measures, but to provide programs that support different firms in different ways. Policies aimed especially at the most constrained firms are likely to yield the strongest benefits.
} 
developed an overlapping generations model of horizontal innovation in the tradition of Romer (1990), with an endogenous distribution of skills, credit market imperfections, and engaging in research activity involves borrowing from financial intermediaries. In the basic model, financial intermediaries provide uncollateralized loans to researchers in the design sector to finance wages, and monitor borrowers at a cost that depends solely on the amount lent and the level of effort required from researchers. It also assumes that there is a one-to-one relationship between the level of effort and the probability of success of a research project. The model was subsequently extended to account - in a highly stylized but tractable way - for the possibility that the intensity of monitoring costs may fall, at least initially, with the number of successful projects. This reduction in costs occurs because the expertise acquired in evaluating profitable (and eventually successful) projects tends to reduce, up to some incompressible level, the cost of screening and monitoring future borrowers.

The key result of our analysis is that, in line with other contributions in the literature, high intermediation costs may adversely affect innovation activity and the rate of economic growth in the long run. In addition, if the cost of borrowing is high, wages in the design sector will be relatively low. As a result, too few individuals may choose to invest in skills and engage in design activities. Thus, lack of access to finance not only exerts a direct, adverse effect on innovation activity (by constraining the number of research projects that are implemented), but also an indirect adverse effect as well. The possibility that financial market imperfections may have an adverse effect on the skill premium, the composition of the labor force, and innovation activity could fruitfully be tested rigorously, with an appropriate set of control variables, using cross-country data. However, it is worth pointing out that these results are prima facie consistent with the empirical evidence of Eichengreen et al. (2014), which suggests that growth slowdowns are less likely in countries where the population has a relatively high level of secondary and tertiary education, and where high-technology products account for a relatively large share of exports.

Moreover, if the intensity of monitoring costs depends on the number of research projects that have received financing (as a result of an information externality for instance), multiple steady states may emerge, one of which characterized as a middle- 
income trap - a phenomenon that has been well documented in the recent literature on developing countries, where (except for a few exceptions) the cost of financial intermediation remains high, the quality of the labor force is weak, and R\&D activity limited. The analysis also showed that an aggressive policy aimed at alleviating credit market imperfections and promoting access to finance by innovators may allow a country to move away from such a trap and lead to an equilibrium characterized by a high share of skilled workers in the population, high growth, and high productivity indesign sectors. Thus, this policy benefits innovation and growth not only directly but also indirectly, by inducing more individuals to acquire an advanced education.

The main focus of our analysis has been on middle-income countries and on providing a rationale for the growth trap that seems to characterize the experience of many of these countries (see Agénor (2017)). In doing so we argued that accounting for the labor market distortions induced by inadequate access to finance is particularly important to understand the interactions between financial intermediation, innovation, and growth. In these countries, the supply of highly-qualified labor remains relatively limited, creating therefore another constraint on innovation activity. By contrast, in developed countries the issue may be less about the quantity of highly-skilled workers and more about the allocation of talent and the provision of adequate incentives to engage in risky entrepreneurial activities. Nevertheless, our analysis also has some relevance for industrial countries, where promoting growth and innovation remain key policy challenges. Indeed, as indicated in our review of the empirical evidence, in many of these countries access to finance remains an equally important constraint on the innovation activity of small and medium-sized firms - and may therefore be a source of a slow-growth equilibrium that bears some of the same characteristics as the middleincome trap that we characterize in our analysis. In such conditions, a sufficiently ambitious policy aimed at promoting access to finance is also essential to escape from a low-growth equilibrium and promote innovation-driven growth.

An extension of the analysis would be to asssume that innovators must finance part of the cost of their projects; this could take the form of pledging of wages earned in period $t$ (as workers) to finance projects implemented in $t+1$ (when agents become entrepreneurs), or alternatively by assuming that bequests across entrepreneurial gen- 
erations provide initial wealth that can also be pledged to secure loans. With "skin in the game," innovators would then produce more effort and this would reduce borrowing costs, promoted R\&D activities, higher wages, more investment in education, and so on. However, this would not affect the qualitative features of the results discussed earlier.

The broad policy implications of our analysis are thus in line with a number of recent academic and policy contributions for both high- and middle-income countries (see Section 2, OECD (2010), and LSE Growth Commission (2013)), which have argued that lack of access to external finance may hamper the development of innovative firms. Because larger firms tend to be less constrained in their operation and growth by their ability to obtain external finance - a possible reflection of their ability to pledge collateral-promoting innovation requires a particular focus on improving access to finance for small and medium firms (Beck et al. (2005), World Bank (2008, 2012), and Dinh and Clarke (2012)). Indeed, in many countries a disproportionate share of innovative research continues to be conducted by this type of firms and organization theory suggests several reasons as to why this may be so (see Holmstrom (1989)). However, our analysis does not provide support for the use of direct subsidies to R\&D firms, especially in the context of developing countries where targeting may be particularly difficult due to a weak institutional environment. ${ }^{24}$ Rather, measures aimed at reducing the cost of collecting, processing, and disseminating information about potential borrowers may prove more effective in some of these countries.

The foregoing analysis emphasized the moral hazard problem that researchers face due to limited liability and the fact that financial intermediaries can determine the success probability of an R\&D investment as a function of the researcher's effort level. In practice, this assumption - even when effort is observable and verifiable - may not fully account for the intrinsically uncertain and unpredictable nature of innovation activities. In addition, it is also possible that the way capital markets can affect the behavior of researchers is to help them improve their capacity for risk-bearing and risksharing, rather than ensuring that they exert a desired optimal level of effort. A more

\footnotetext{
${ }^{24}$ As noted in the Introduction, Morales (2003) offers another argument that suggests that a subsidy to financial intermediation may be more effective than a direct subsidy to R\&D activity.
} 
general model, with a more detailed stochastic structure, would therefore be needed to account for these other features of the relationship between finance and innovation. However, while valuable in their own right, these extensions would not significantly affect the indirect channel highlighted in the present setting, which operates through the incentives to acquire skills.

Finally, although we did not introduce explicitly capital markets other than the credit market in our model, our analysis suggests that there may be a greater role for private finance to play in developing countries. One form that this role can take is through the creation of credit bureaus, designed to share information about potential borrowers. However, in a number of countries free-rider problems and weak institutions have limited the potential benefits of these bureaus, suggesting that government intervention may be necessary during an initial stage. Another important area would be to promote the development of a private sector venture capital industry that provides incentives for risk taking and financing for new and young innovative firms. By and large, the evidence reviewed earlier suggests that, for industrial countries, access to venture capital has a significant impact on innovation (see also Da Rin et al. (2013)). In developing countries, however, promoting venture capital markets may also require improving contract enforcement mechanisms and better protection of intellectual property rights.

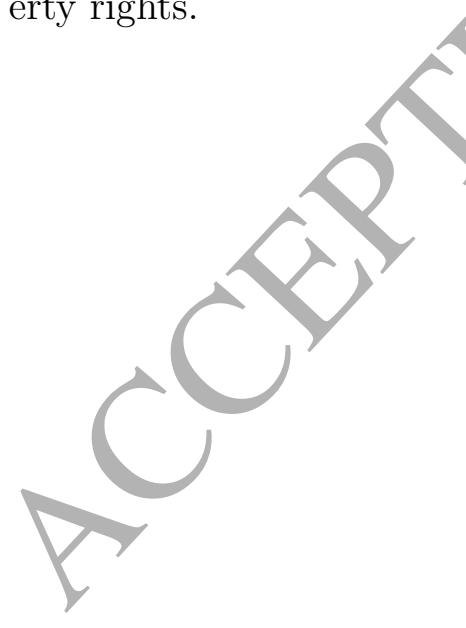




\section{Appendix}

To study the dynamics, note first that substituting (20) in (16) yields

$$
Y_{t}=m_{t}^{\gamma / \eta}\left[\gamma \eta\left(\frac{Y_{t}}{K_{t}}\right) m_{t}^{-1}\right]^{\gamma} K_{t}
$$

which can be rearranged to give

$$
\frac{Y_{t}}{K_{t}}=\Lambda m_{t}^{\gamma\left(\eta^{-1}-1\right) /(1-\gamma)},
$$

where $\Lambda=(\gamma \eta)^{\gamma /(1-\gamma)}$.

To determine the equilibrium wage ratio, note that from equations (12), (24), and (25),

$$
\begin{gathered}
w_{t}^{U}=\beta Y_{t} / N_{t}^{U}, \\
w_{t}^{S}=\frac{p_{t}^{R} A_{t}}{R_{t}^{L} N}=\frac{p_{t}^{R} M_{t}}{R_{t}^{L} N} .
\end{gathered}
$$

Thus

$$
\frac{w_{t}^{S}}{w_{t}^{U}}=\frac{p_{t}^{R} M_{t}}{R_{t}^{L} \beta Y_{t}}\left(\frac{N_{t}^{U}}{N}\right)
$$

From (4), $N_{t}^{U} / N=a_{t}^{C}$, and from (21) and (22),

$$
p_{t}^{R}=(1-\eta) \gamma\left(\frac{Y_{t}}{M_{t}}\right)
$$

Substituting these two results in (A4) yields

$$
\frac{w_{t}^{S}}{w_{t}^{U}}=\frac{(1-\eta) \gamma}{\beta R_{t}^{L}} a_{t}^{C}
$$

which corresponds to equation (33) in the text.

From (1), $a_{t}^{C}=\left(w_{t}^{U} / w_{t}^{S}\right)+\mu$. Substituting (A6) in this expression yields

$$
a_{t}^{C}-\frac{\beta R_{t}^{L}}{(1-\eta) \gamma a_{t}^{C}}=\mu .
$$

Setting $\mu=0$ for simplicity yields ${ }^{25}$

$$
a_{t}^{C}=G\left(R_{t}^{L}\right)=\left[\frac{\beta R_{t}^{L}}{(1-\eta) \gamma}\right]^{0.5}
$$

\footnotetext{
${ }^{25}$ If $\mu>0$, equation (A7) yields the quadratic form $\left(a_{t}^{C}\right)^{2}-\mu a_{t}^{C}-\left[\beta R_{t}^{L} /(1-\eta) \gamma\right]=0$. Because $\mu^{2}+4\left[\beta R_{t}^{L} /(1-\eta) \gamma\right]>0$, both roots are real. And because the constant term in the quadratic form $-\left[\beta R_{t}^{L} /(1-\eta) \gamma\right]$, which by definition is equal to the product of the roots, is negative, the roots are of opposite sign. There is only one positive root, which is the one to consider given the restriction $a_{t}^{C}>0$. Thus, as in (A8), when $\mu>0$ the relationship between $a_{t}^{C}$ and $R_{t}^{L}$ is also positive.
} 
which corresponds to equation (34) in the text.

From (31),

$$
q_{t} R_{t}^{L}-R^{W}-\frac{\chi\left(q_{t}-q_{m}\right)^{2}}{2}=0
$$

that is, substituting for $q_{t}$ from (30),

$$
\Gamma\left(R^{L}, \chi\right)=R^{L}-\frac{\chi R^{W}+0.5\left(R^{L}\right)^{2}}{\chi q_{m}+R^{L}}=0 .
$$

Thus, $R_{t}^{L}$ is constant as long as $\chi$ is constant. From (30) and (A8), $q$ and $a^{C}$ are also constant.

Using the implicit function theorem, $d R^{L} / d \chi=-\Gamma_{\chi} / \Gamma_{R^{L}}$. Equation (A8) yields therefore

that is,

$$
\Gamma_{\chi}=-\frac{\left(\chi q_{m}+R^{L}\right) R^{W}-\left[\chi R^{W}+0.5\left(R^{L}\right)^{2}\right] q_{m}}{\left(\chi q_{m}+R^{L}\right)^{2}},
$$

$$
\Gamma_{\chi}=-\frac{R^{L}\left(R^{W}-q_{m} 0.5 R^{L}\right)}{\left(\chi q_{m}+R^{L}\right)^{2}} \lessgtr 0 .
$$

Similarly,

$$
\Gamma_{R^{L}}=1-\frac{\left(\chi q_{m}+R^{L}\right) R^{L}-\left(\chi R^{W}+0.5 R^{2}\right) \cdot 1}{\left(\chi q_{m}+R^{L}\right)^{2}},
$$

that is,

$$
\Gamma_{R^{L}}=\frac{\left(\chi q_{m}\right)^{2}+\chi q_{m} R^{L}+0.5\left(R^{L}\right)^{2}+\chi R^{W}}{\left(\chi q_{m}+R^{L}\right)^{2}}>0 .
$$

To ensure that $d R^{L} / d \chi>0$ requires therefore $\Gamma_{\chi}<0$, that is, $R^{W}-q_{m} 0.5 R^{L}>$ 0 or equivalently $R^{L} / R^{W}<1 / q_{m} 0.5$, a relatively mild condition in practice. With $d R^{L} / d \chi>0$, equation (A8) implies that $d a^{C} / d \chi>0$, whereas (31) implies that $d q / d \chi \lessgtr 0$.

Now, consider the dynamics of the capital stock. Writing (32) again for convenience:

$$
K_{t+1}=\sigma\left(w_{t}^{U} N_{t}^{U}+w_{t}^{S} N_{t}^{S}\right)
$$

and using (A2) and (A3) yields

$$
K_{t+1}=\sigma\left\{\beta Y_{t}+\left(\frac{p_{t}^{R} M_{t}}{R_{t}^{L}}\right)\left(\frac{N_{t}^{S}}{N}\right)\right\} .
$$

Noting from (5) that $N_{t}^{S} / N=0.5\left[1-\left(a_{t}^{C}\right)^{2}\right]$ yields

$$
K_{t+1}=\sigma\left\{\beta Y_{t}+\left(\frac{p_{t}^{R} M_{t}}{R_{t}^{L}}\right) 0.5\left[1-\left(a_{t}^{C}\right)^{2}\right]\right\},
$$


and substituting from $(\mathrm{A} 5) p_{t}^{R}=(1-\eta) \gamma\left(Y_{t} / M_{t}\right)$,

$$
K_{t+1}=\sigma\left\{\beta+\Omega \frac{\left[1-\left(a_{t}^{C}\right)^{2}\right]}{R_{t}^{L}}\right\} Y_{t}
$$

where $\Omega=0.5(1-\eta) \gamma$.

Equation (23) can be rewritten as, using (5) again and (24),

$$
\frac{M_{t+1}}{M_{t}}=1+q 0.5\left[1-\left(a^{C}\right)^{2}\right] .
$$

Dividing this expression by (A9) and noting that $M_{t} / Y_{t}=\left(Y_{t} / K_{t}\right)^{-1} m_{t}$ yields

$$
m_{t+1}=\frac{1+q 0.5\left[1-\left(a^{C}\right)^{2}\right]}{\sigma\left\{\beta+\left(R^{L}\right)^{-1} \Omega\left[1-\left(a^{C}\right)^{2}\right]\right\}}\left(\frac{Y_{t}}{K_{t}}\right)^{-1} m_{t},
$$

that is, using (A1) and (A8),

$$
m_{t+1}=\Phi\left(m_{t}\right)=\frac{\Lambda^{-1}\left\{1+q 0.5\left[1-G\left(R^{L}\right)^{2}\right]\right\}}{\sigma\left[\beta+\left(R^{L}\right)^{-1} \Omega\left[1-G\left(R^{L}\right)^{2}\right]\right.} m_{t}^{\left(1-\gamma \eta^{-1}\right) /(1-\gamma)},
$$

which corresponds to equation (35) in the text

To determine the growth rate of final output, note that from (A1) and (A9),

$$
\frac{Y_{t+1}}{Y_{t}}=\Lambda m_{t+1}^{\gamma\left(\eta^{-1}-1\right) /(1-\gamma)} \sigma\left\{\beta+\Omega \frac{\left[1-G\left(R^{L}\right)^{2}\right]}{R^{L}}\right\} .
$$

Equation (A11) yields the steady-state solution (36) in the text. 


\section{References}

Acemoglu, Daron, Introduction to Modern Economic Growth, Princeton University Press (Princeton, New Jersey: 2009).

Acharya, Viral V., and Krishnamurthy V. Subramanian, "Bankruptcy Codes and Innovation," Review of Financial Studies, 22 (December 2009), 4949-88.

Agénor, Pierre-Richard, The Economics of Adjustment and Growth, Harvard University Press (Cambridge, Mas.: 2004).

_ - "Caught in the Middle? The Economics of Middle-Income Traps," Journal of Economic Surveys, forthcoming (June 2017).

Agénor, Pierre-Richard, and Otaviano Canuto, "Middle-Income Growth Traps," Research in Economics, 69 (December 2015), 641-60.

Aghion, Philippe, and Peter Howitt, The Economics of Growth, MIT Press (Cambridge, Mass.: 2009).

Aghion, Philippe, Peter Howitt, and David Mayer-Foulkes, "The Effect of Financial Development on Convergence: Theory and Evidence," Quarterly Journal of Economics, 120 (January 2005), 173-222.

Ang, James B., "Research, Technological Change and Financial Liberalization in South Korea," Journal of Macroeconomics, 32 (March 2010), 457-68.

—_, "Financial Development, Liberalization and Technological Deepening," European Economic Review, 55 (June 2011), 688-701.

Aiyar, Shekhar, Romain Duval, Damien Puy, Yiqun Wu, and Longmei Zhang, "Growth Slowdowns and the Middle-Income Trap," Working Paper No. 13/71, International Monetary Fund (March 2013).

Ayyagari, Meghana, Asli Demirgüç-Kunt, and Vojislav Maksimovic, "Firm Innovation in Emerging Markets: The Roles of Governance and Finance," Journal of Financial and Quantitative Analysis, 46 (September 2011), 1545-80.

Azariadis, Costas, "The Theory of Poverty Traps: What have we Learned?," in Poverty Traps, ed. by Samuel Bowles, Steven N. Durlauf, and Karla Hoff, Princeton University Press (Princeton, N.J.: 2006).

Besanko, David, and George Kanatas, "Credit Market Equilibrium with Bank Monitoring and Moral Hazard," Review of Financial Studies, 6 (January 1993), 213-32.

Beck, Thorsten, Asli Demirguc-Kunt, and Vojislav Maksimovic, "Financial and Legal Constraints to Firm Growth: Does Firm Size Matter?," Journal of Finance, 60 (March 2005), 137-77.

Blackburn, Keith, and Victor T. Hung, "A Theory of Growth, Financial Development and Trade" Economica, 65 (February 1998), 107-24.

Brown, James R., Gustav Martinsson, and Bruce C. Petersen, "Do Financing Constraints Matter for R\&D?," European Economic Review, 56 (November 2012), 1512-29.

Da Rin, Marco, Thomas F. Hellmann, and Manju Puri, "A Survey of Venture Capital Research," in Handbook of the Economics of Finance, Vol. 2A, ed. by. George M. Constantinides, Milton Harris, and René Stulz, North Holland (Amsterdam: 2013). 
De la Fuente, Angel, and José M. Marín, "Innovation, Bank Monitoring, and Endogenous Financial Development," Journal of Monetary Economics, 38 (October 1996), 269-301.

De Mel, Suresh, David McKenzie, and Christopher Woodruff, "Innovative Firms or Innovative Owners? Determinants of Innovation in Micro, Small, and Medium Enterprises," Policy Research Working Paper No. 4934, World Bank (May 2009).

Dinh, Hinh T., and George R. G. Clarke, eds., Performance of Manufacturing Firms in Africa: An Empirical Analysis, World Bank (Washington DC: 2012).

Dinopoulos, Elias, and Peter Thompson, "Endogenous Growth in a Cross-Section of Countries," Journal of International Economics, 51 (August 2000), 335-62.

Efthyvoulou, Georgios, and Priit Vahter, "Financial Constraints and Innovation Performance: Are all Firms Similar?," unpublished, University of Birmingham (August 2012).

Eichengreen, Barry, Donghyun Park, and Kwanho Shin, "When Fast Economies Slow Down: International Evidence and Implications for China," Asian Economic Papers, 11 (March 2012), 42-87.

— , "Growth Slowdowns Redux," Japan and the World Economy, 32 (November 2014), $65-84$.

Faria, Ana Paula, and Natália Barbosa, "Does Venture Capital really Foster Innovation?," Economics Letters, 122 (February 2014), 129-31.

Felipe, Jesus, Arnelyn Abdon, and Utsav Kumar, "Tracking the Middle-Income Trap: What is it, who is in it, and why?," Working Paper No. 715, Levy Economics Institute (April 2012).

Galetovic, Alexander, "Specialization, Intermediation, and Growth," Journal of Monetary Economics, 38 (December 1996), 549-59.

Gorodnichenko, Yuriy, and Monika Schnitzer, "Financial Constraints and Innovation: Why Poor Countries don't Catch up," Journal of European Economic Association, 11 (October 2013), 1115-52.

Hall, Bronwyn H., and Lerner Josh, "The Financing of R\&D and Innovation," in Handbook of the Economics of Innovation, ed. by Bronwyn H. Hall and N. Rosenberg, North Holland (Amsterdam: 2010).

Harrison, Paul, Oren Sussman, and Joseph Zeira, "Finance and Growth: Theory and New Evidence," Discussion Paper No. 1999-35, Federal Reserve Board (July 1999).

Hirukawa, Masayuki, and Masako Ueda, "Venture Capital and Innovation: Which is First?," Pacific Economic Review, 16 (December 2011), 421-65.

Holmstrom, Bengt, "Agency Costs and Innovation," Journal of Economic Behavior and Organization, 12 (December 1989), 305-27.

Hottenrott, Hanna, and Bettina Peters, "Innovative Capability and Financing Constraints for Innovation: More Money, more Innovation?," Review of Economics and Statistics, 94 (November 2012), 1126-42.

Hsu, Po-Hsuan, Xuan Tian, Yan Xu, "Financial Development and Innovation: CrossCountry Evidence," Journal of Financial Economics, 112 (April 2014), 116-35.

Ilyina, Anna, and Roberto Samaniego, "Technology and Financial Development," Journal of Money, Credit and Banking, 43 (August 2011), 899-921. 
Im, Fernando G., and David Rosenblatt, "Middle-Income Traps: A Conceptual and Empirical Survey," Policy Research Working Paper No. 6594, World Bank (September 2013).

Inter-American Development Bank, "The Importance of Ideas: Innovation and Productivity in Latin America," in The Age of Productivity, ed. by Carmen Pagés, InterAmerican Development Bank (Washington DC: 2010).

International Finance Corporation, Assessing Private Sector Contributions to Job Creation, IFC publications (Washington DC: 2013).

Jimenez, Emmanuel, Vy Nguyen, and Harry A. Patrinos, "Stuck in the Middle? 'Human Capital Development and Economic Growth in Malaysia and Thailand," Policy Research Working Paper No. 6283, World Bank (November 2012)

Keuschnigg, Christian, "Optimal Public Policy for Venture Capital Backed Innovation," Discussion Paper No. 2003-09, University of St. Gallen (March 2003),

Laeven, Luc, Ross Levine, and Stelios Michalopoulos, "Financial Innovation and Endogenous Growth," Journal of Financial Intermediation, 24 (January 2015), 1-24.

LSE Growth Commission, Investing for Prosperity: Skills, Infrastructure and Innovation, London School of Economics (London: 2013).

Maskus, Keith E., Rebecca Neumann, and Tobias Seidel, "How National and International Financial Development Affect Industrial R\&D," European Economic Review, 56 (January 2012), 72-83.

Lilischkis, Stefan, "Policies in Support of High-Growth Innovative SMEs," INNO-Grips Policy Brief No. 2, European Commission (June 2011).

Morales, María F., "Financial Intermediation in a Model of Growth through Creative Destruction," Macroeconomic Dynamics, 7 (June 2003), 363-93.

OECD, The OECD Innovation Strategy: Getting a Head Start on Tomorrow, OECD (Paris: 2010).

Popov, Alexander, and Peter Roosenboom, "Venture Capital and Industrial Innovation: Evidence from Europe," Economic Policy, 27 (July 2012), 447-82.

Romer, Paul M., "Endogenous, Technological Change," Journal of Political Economy, 98 (October 1990), s71-s102.

Savignac, Frédérique, "Impact of Financial Constraints on Innovation: What can be Learned from a Direct Measure?," Economics of Innovation and New Technology, 17 (August 2008), 553-69.

Schumpeter, Joseph A., The Theory of Economic Development, Oxford University Press (New York: 1961).

Sharpe, Samantha, "Risk Capital and Innovation: Venture Capital Literature Review," unpublished, University of Cambridge (August 2009).

Silva, Eilipe, and Carlos Carreira, "Do Financial Constraints Threaten the Innovation Process? Evidence from Portuguese Firms," Economics of Innovation and New Technology, 21 (November 2012), 701-36.

Tanaka, Hitoshi, and Tatsuro Iwaisako, "Product Cycles, Endogenous Skill Acquisition, and Wage Inequality," Canadian Journal of Economics, 42 (February 2009), 300-31. 
World Bank, Finance for All: Policies and Pitfalls in Expanding Access, Policy Research Report, World Bank (Washington DC: 2008).

, Jobs, World Development Report, World Bank (Washington DC: 2012).

- Financial Inclusion, Global Financial Development Report, World Bank (Washington DC: 2014).

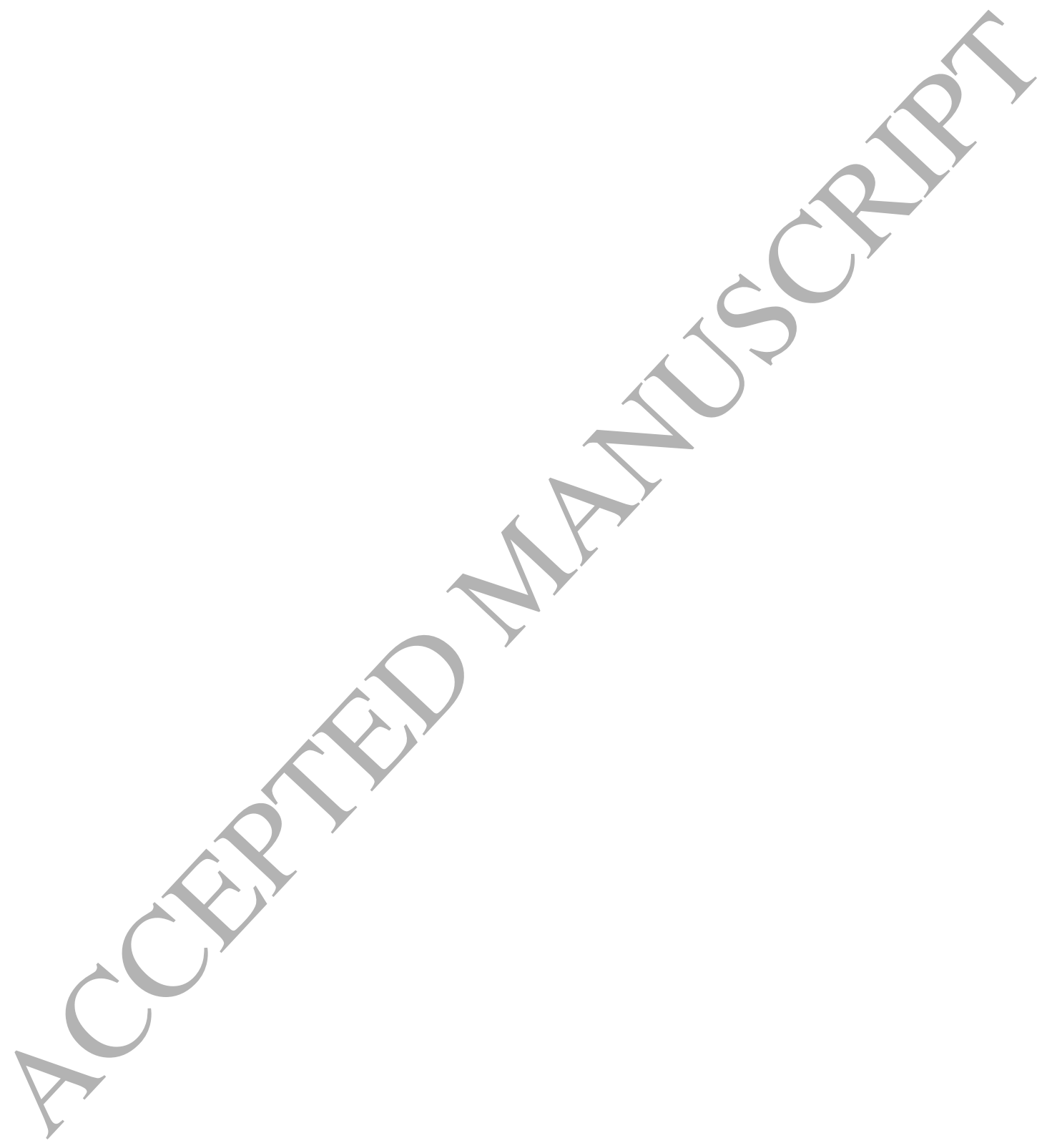



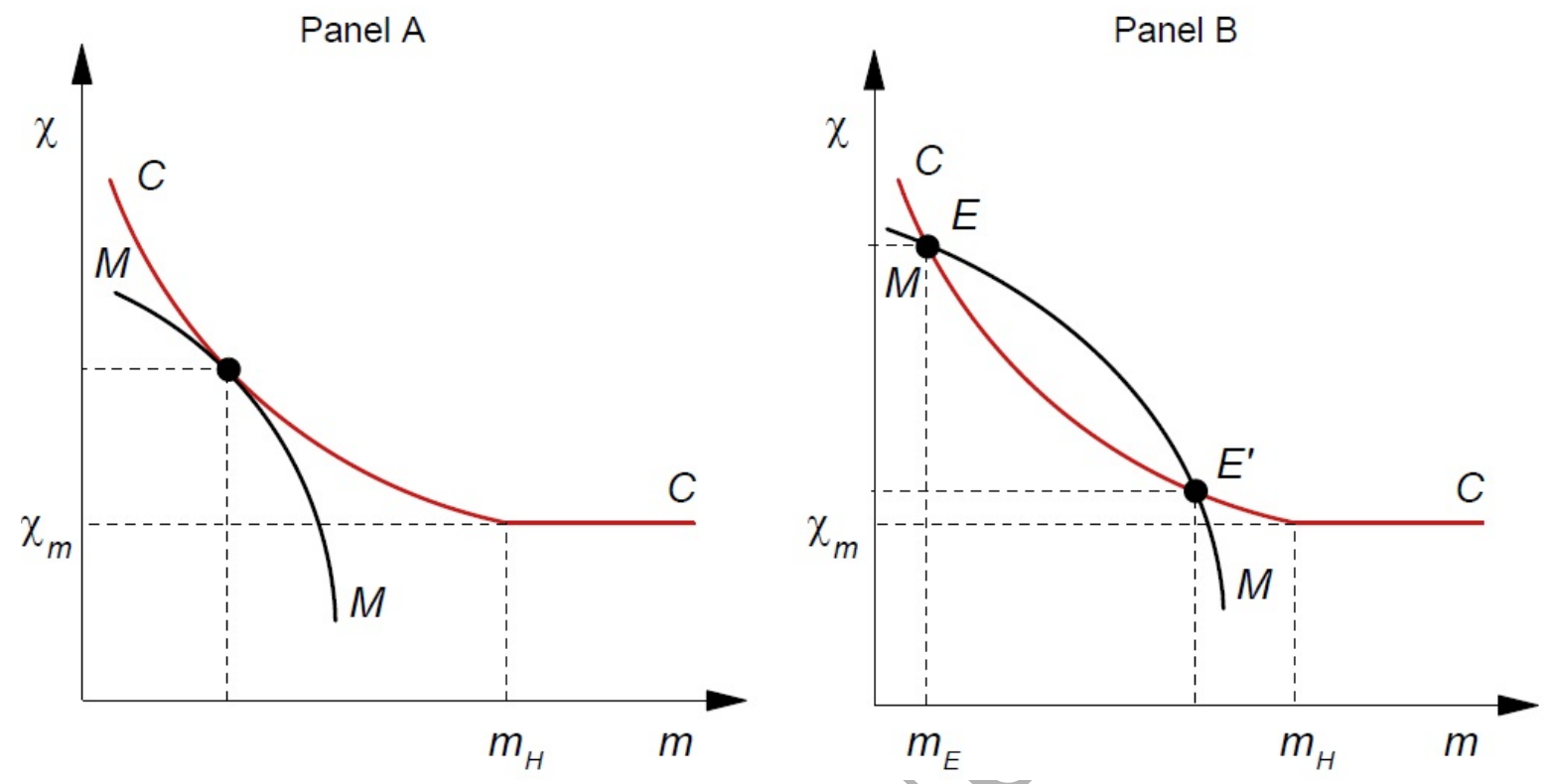

Figure 1: Equilibrium with Endogenous Unit Monitoring Costs: Decreasing and Concave $M M$
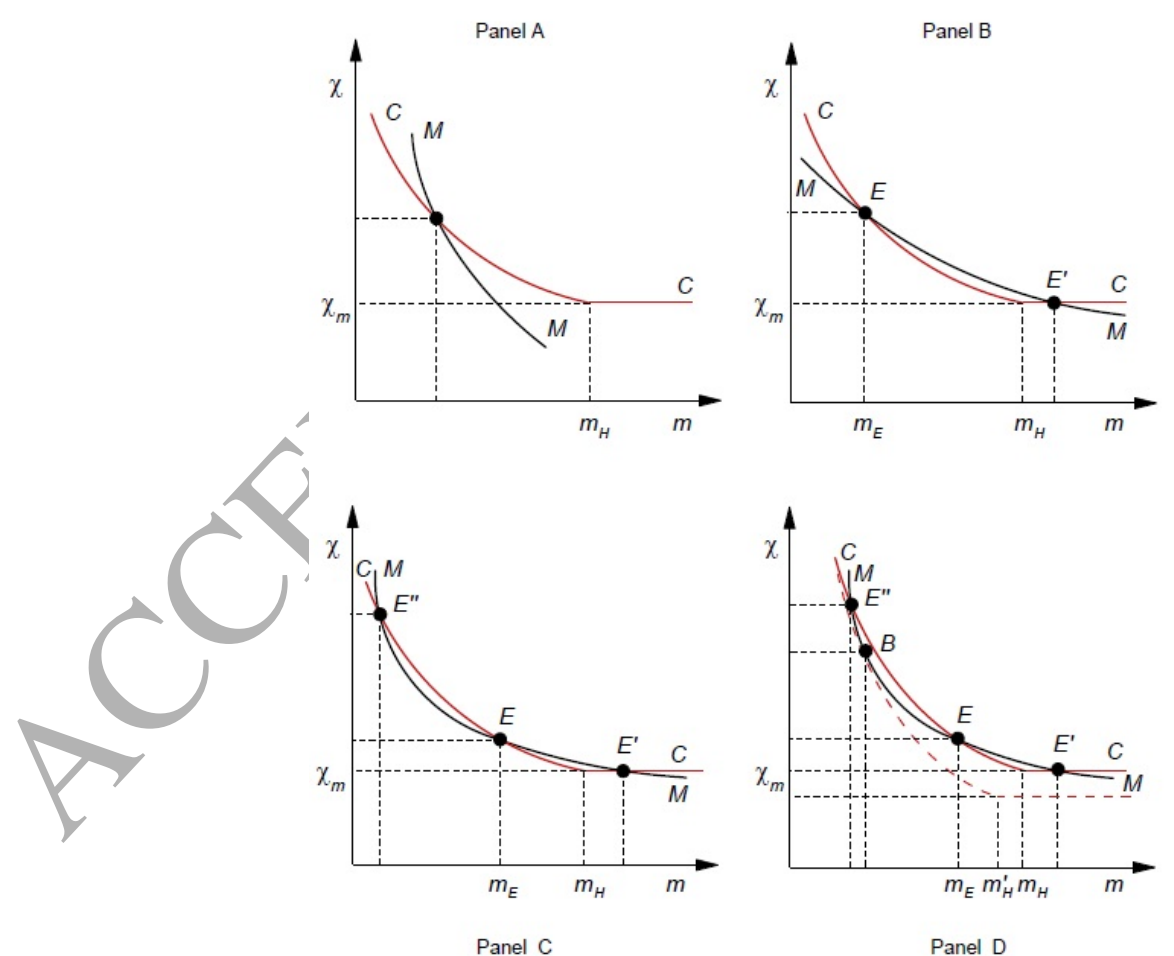

Figure 2: Equilibrium and the Role of Public Policy: Decreasing and Convex $M M$ 